University of Louisville

ThinkIR: The University of Louisville's Institutional Repository

Electronic Theses and Dissertations

8-2020

\title{
Peer verbal sexual harassment in early adolescence: a feminist and sexual scripts theoretical approach.
}

Shawn M. Rolfe

University of Louisville

Follow this and additional works at: https://ir.library.louisville.edu/etd

Part of the Developmental Psychology Commons, Development Studies Commons, Domestic and Intimate Partner Violence Commons, Experimental Analysis of Behavior Commons, Family, Life Course, and Society Commons, Gender and Sexuality Commons, Health Policy Commons, Junior High, Intermediate, Middle School Education and Teaching Commons, Other Public Affairs, Public Policy and Public Administration Commons, Public Policy Commons, Secondary Education Commons, and the Social Policy Commons

\section{Recommended Citation}

Rolfe, Shawn M., "Peer verbal sexual harassment in early adolescence: a feminist and sexual scripts theoretical approach." (2020). Electronic Theses and Dissertations. Paper 3576.

https://doi.org/10.18297/etd/3576

This Doctoral Dissertation is brought to you for free and open access by ThinkIR: The University of Louisville's Institutional Repository. It has been accepted for inclusion in Electronic Theses and Dissertations by an authorized administrator of ThinkIR: The University of Louisville's Institutional Repository. This title appears here courtesy of the author, who has retained all other copyrights. For more information, please contact thinkir@louisville.edu. 
PEER VERBAL SEXUAL HARASSMENT IN EARLY ADOLESCENCE: A FEMINIST AND SEXUAL SCRIPTS THEORETICAL APPROACH By

Shawn M. Rolfe

B.A., Wright State University, 2013

M.A., University of Louisville, 2015

\begin{abstract}
A Dissertation
Submitted to the Faculty of the in Partial Fulfillment of the Requirements for the Degree of

Doctor of Philosophy in Criminal Justice

Department of Criminal Justice University of Louisville Louisville, Kentucky
\end{abstract} College of Arts and Sciences of the University of Louisville

August 2020 
Copyright 2020 by Shawn Michael Rolfe

All rights reserved. 

PEER VERBAL SEXUAL HARASSMENT IN EARLY ADOLESCENCE: A FEMINIST AND SEXUAL SCRIPTS THEORETICAL APPROACH

By

Shawn M. Rolfe

B.A., Wright State University, 2013

M.A., University of Louisville, 2015

A Dissertation Approved on

June 16, 2020

by the following Dissertation Committee:

Dr. Deborah G. Keeling, Dissertation Chair

Dr. Viviana Andreescu, Co-Chair

Dr. Cherie Dawson-Edwards, Committee Member

Dr. Ryan D. Schroeder, Committee Member 


\section{DEDICATION}

This dissertation is dedicated to my partner, daughter, and parents

Mrs. Sheila Rolfe and Ms. Kayla Rolfe,

Mr. and Mrs. Halliard and Beverly Brown

and

Mr. and Mrs. Robert and Joyce Rolfe,

without their constant love and support, none of this would have been possible. 


\section{ACKNOWLEDGEMENTS}

Whether directly or indirectly, there have been a lot of people who have influenced me to aspire to be an agent of change through research. To all of them, thank you. There are several professors that must be acknowledged as well. First, Dr. Karen Lahm for seeing my love for sociology and criminology and its use to impact the lives of others through social change and justice and encouraging me to pursue graduate school. Several other professors also took me under their wing and mentored me throughout my journey. The first to do so was Dr. Ryan Schroeder. I will never be able to thank you enough for the time you have spent teaching and mentoring me, as well as being a good friend. I am also grateful for the mentorship and friendship of Dr. Cherie DawsonEdwards over the years. Dr. Viviana Andreescu provided constant guidance throughout my time in the doctoral program, for which I am very grateful. I am also tremendously thankful to Dr. Deborah Keeling for her willingness to give her time and to serve as my dissertation chair. Without question, I am forever appreciative for the encouragement, discernment, and the countless hours that she, my dissertation committee, and others who have invested in my success to become a scholar and colleague. Finally, I want to thank my partner Sheila and daughter Kayla for their unwavering support and encouragement to pursue and achieve my dreams. They have been and will continue to always be my greatest champion. 


\section{ABSTRACT \\ PEER VERBAL SEXUAL HARASSMENT IN EARLY ADOLESCENCE: A FEMINIST AND SEXUAL SCRIPTS THEORETICAL APPROACH Shawn M. Rolfe}

June 16, 2020

Until recently, sexual harassment research has focused primarily on adults and college and high school students with little attention given to younger students. While recent research has noted sexual harassment occurs among younger students, the literature addressing sexual harassment among middle school students is still sparse. Additionally, most studies of sexual harassment have focused on sexual harassment generally, with no distinction made between verbal and sexual harassment. In fact, only limited research has been exclusively conducted on verbal sexual harassment. Using selfreport data, the current study adds to the literature by examining the nature of verbal sexual harassment as well as selected characteristics of the victims of sexual harassment through the lens of Gender Order Theory and Social Script Theory. Additionally, this study seeks to assess the effectiveness of one school-based violence reduction program, Shifting Boundaries, as implemented among $6^{\text {th }}$ and $7^{\text {th }}$ graders in 30 middle schools in the New York City School System in 2009-2010. The findings suggest that boys are the primary perpetrator of verbal sexual harassment against both genders, and the sexual harassment program was not overly effective in reducing perpetration and victimization 
among this population. Additional findings, limitations, and policy implications are discussed. 


\section{TABLE OF CONTENTS}

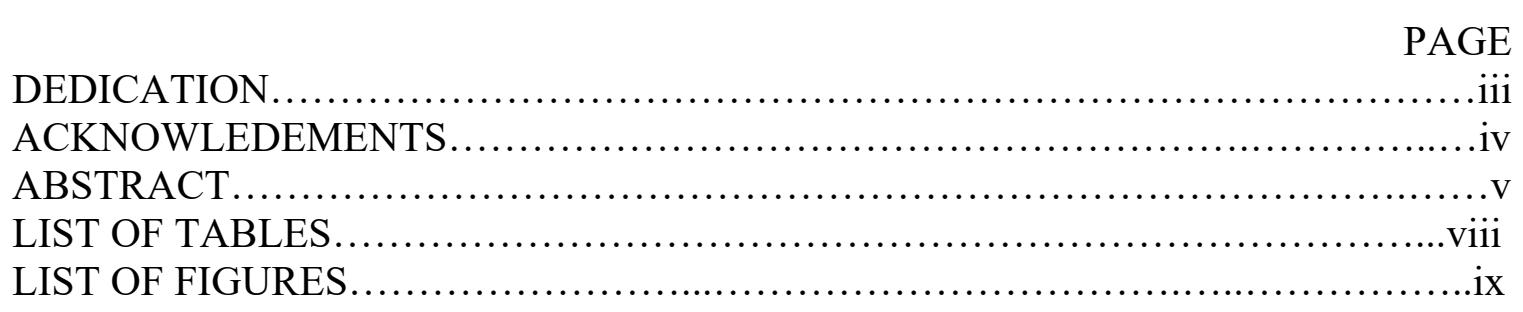

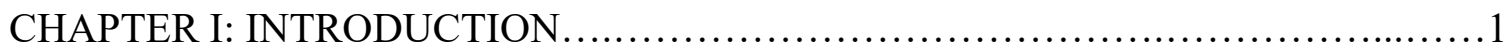

CHAPTER II: REVIEW OF THE LITERATURE............................... 6

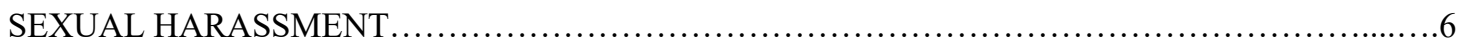

PREVALENCE OF SEXUAL HARASSMENT IN K-12 SCHOOLS $\ldots \ldots \ldots \ldots \ldots \ldots \ldots \ldots \ldots \ldots \ldots \ldots$

AGE AND SEXUAL HARASSMENT VICTIMIZATION $\ldots \ldots \ldots \ldots \ldots \ldots \ldots \ldots \ldots \ldots \ldots \ldots \ldots \ldots \ldots$

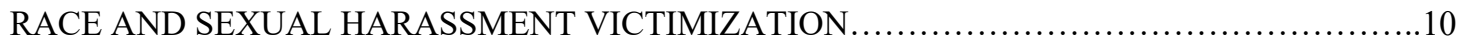

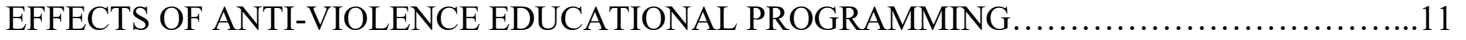

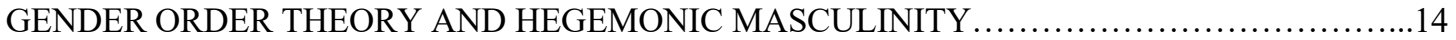

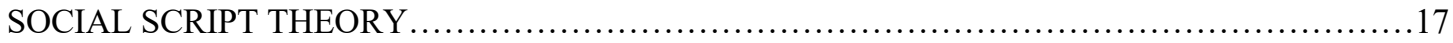

CHAPTER III: METHODOLOGY ...........................................22

CHAPTER IV: ANALYSIS ................................................... 32

CHAPTER V: DISSCUSSION ................................................

REFERENCES........................................................79

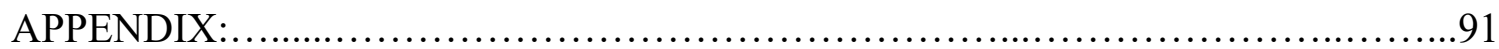

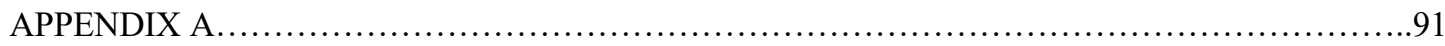

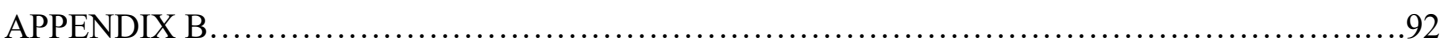

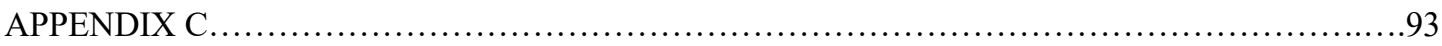

CURRICULUM VITAE..................................................... 94 


\section{LIST OF TABLES}

TABLE

PAGE

1. Descriptive Statistics for VSH Victimization Among Middle School Students.......35

2. Descriptive Statistics for VSH Victimization by Gender........................39

3. Bivariate Analysis - Paired Sample t-test for VSH Victimization (Post- vs. Pre-test)...42

4. Correlation Matrix - Overall Sample........................................44

5. Correlation Matrix by Gender........................................... 45

6. Multinomial Logit Estimate for VSH Victimization in Early Adolescences.........50

7. Multinomial Logit Estimate for VSH Victimization in Early Adolescences.........54

8. Covariate Balance for Program Selection Before and After Matching...............59

9. Multinomial Logit Est. for VSH Victimization in Early Adolescence (PSM).......60

10. Multinomial Logit Est. for VSH Victimization in Early Adolescence (PSM).......61 


\section{LIST OF FIGURES}

FIGURE

PAGE

1. Post-test Victimization by Gender................................................... 36 


\section{CHAPTER I}

\section{INTRODUCTION}

The \#MeToo movement sparked in Fall 2017 when reported sexual misconduct

by Harvey Weinstein brought the issue of non-consensual and unwanted sexual behaviors to widespread public attention. As public awareness of this problem has increased, so has the interest of researchers in analyses of patterns and frequency of sexual misconduct (McMahon, 2019). And, while definitions of what forms sexual misconduct may take have varied across this research, there is general agreement that it may take many forms and that a central component of these acts is not truly sexual in nature but is, instead, based on power differentials and control (Uggen \& Blackstone, 2004). Additionally, most scholars agree that sexual misconduct includes actions that can be viewed on a continuum from physical acts such as sexual assault to name-calling (Hulin et al., 1996).

Sexual harassment is one from of sexual misconduct. And, while competing definitions exist, is defined officially as:

Unwelcomed sexual advances, requests for sexual favors, and other verbal or physical conduct of a sexual nature constitute sexual harassment when this conduct explicitly or implicitly affects an individual's employment, unreasonably interferes with an individual's work performance, or creates an intimidating, hostile or offensive work environment. (U.S. Equal Opportunity Commission, 1980).

As with sexual misconduct, sexual harassment may include varied behaviors ranging from unwanted sexual touching to name calling (Timmerman, 2003; Lichty \& Campbell, 2012). The distinction between verbal and physical sexual harassment is not 
entirely clear or significantly delineated in prior sexual harassment research. Generally, verbal sexual harassment involves non-physical contact and primarily refers to sexual comments, jokes, homophobic-name-calling, and gestures, whereas physical sexual harassment refers to some form of inappropriate sexual contact such as brushing up against someone in a sexual way or touching someone in their private areas (American Association of University Women [AAUW], 2001). Despite the important distinctions, the vast majority of prior research addressing sexual harassment has combined verbal and physical sexual harassment into one measure (AAUW, 2001, 2011; Espelage et al., 2015; Gruber \& Fineran, 2007, 2008) or focused solely on physical sexual harassment (Levine, 2017; Pelligrini, 2001), thereby neglecting the unique correlates and effects of verbal sexual harassment.

The consequences of sexual harassment have been documented. They range from diminished mental (e.g., fear, depression, anxiety, and low self-esteem) and physical health (e.g., loss of appetite, and loss of sleep) to life satisfaction, substance abuse, and suicidal ideation (Ackard \& Neumark-Szainer, 2002; Corbett et al., 1993; Dahlqvist et al., 2016; Gruber \& Fineran, 2007, 2008; Hand \& Sanchez, 2000; Ormerod et al., 2008; Stein et al., 1993; Tully, 2010). Sexual harassment victimization has also caused students to revert to social isolation and for some, has affected their academic performance (Offenhauer \& Buchalter, 2011). Other long-term consequences identified are continued social isolation and an increased risk of future sexual harassment revictimization (Banyard \& Cross, 2008; Exner-Cortens et al., 2013; Finkelhor et al., 2007). And, while some might discount the consequences of verbal sexual harassment, research has shown that verbal and physical sexual harassment can both have deleterious consequences 
(Hand \& Sanchez, 2000).

Sexual harassment in the workplace has been well documented (Gutek, 1985, p.46; Fitzgerald, 1993; Galesic \& Tourangeau, 2007; Conte, 2010; McDonald, 2012; Sojo et al., 2016). More recently, however, researchers have documented sexual misconduct, including sexual harassment in schools, universities and colleges. Recognizing the prevalence of sexual harassment in educational institutions, a more specific definition has been developed to include educational settings.

Sexual harassment is defined as unwelcome sexual advances, requests for sexual favors, and other verbal, nonverbal, or physical conduct of a sexual nature by an employee, by another student, or by a third party, that is sufficiently severe, persistent, or pervasive to limit a student's ability to participate in or benefit from an education program or activity, or to create a hostile or abusive educational environment (U.S. Department of Education, Office for Civil Rights, 1997, p. 12038).

Much of the research in educational settings has concentrated on sexual harassment among college and university students (Benson \& Thomson, 1982; Reilly et al., 1986; Hill \& Silva, 2005; Cantor et al., 2015; Wolff et al., 2017; Klein \& Martin, 2019; Crittenden et al., 2018). But exposure to sexual harassment is not limited to college-age students. A national study conducted in 2011 by the American Association of University Women (AAUW) found that 81 percent of students in 8-11 grades reported sexual harassment incident at some point in their lives at school. And, while we have existing studies that have assessed sexual harassment among college-aged students as well as students in $8^{\text {th }}$ through $12^{\text {th }}$ grades, research has suggested that sexual harassment begins even earlier (Espelage \& Holt, 2007; Espelage et al., 2012).

Based on existing research, very little is known about sexual harassment among students prior to the $8^{\text {th }}$ grade. And, while research (AAUW, 2001, 2011) has shown that 
sexual harassment occurs in our K-12 school system, there are significant issues with the identification and reporting of sexual misconduct. In fact, many school officials do not know how to recognize the various forms of sexual misconduct, for example, not knowing how to differentiate between bullying and sexual harassment (Charmaraman et al., 2013). This has led to the promotion of a "bullying framework" throughout our educational system, when in fact the behaviors are sexual harassment (Stein, 2010). This is evidenced in a recent investigation by the U.S. Department of Education's Office for Civil Rights into the Palo Alto school district's failure to investigate sexual harassment and assaults that had taken place on and off their campuses (Kadvany, 2017). Likewise, Chicago's school district was cited for similar infractions of not investigating or further protecting their students from this type of violence (Green, 2019).

As sexual harassment, both verbal and physical, has come to be recognized as a problem within educational institutions, programs have been developed and implemented to prevent sexual harassment among students. According to a national survey published in 2011, 65 percent of students in the United States between the age of 5 and 17 were exposed to a school-based violence prevention program. Of those, 21 percent participated in some form of a sexual assault prevention program (Finkelhor et al., 2014). However, there is broad variability in what constitutes a "prevention" program, what constitutes "participation" in a school-based program, a failure to differentiate between the types of school violence in the school programming, and limited attempts to follow-up on program effectiveness (Finkelhor et al., 2014).

The purpose of the current research is to contribute to the literature through an examination of verbal sexual harassment among middle school $\left(6^{\text {th }}\right.$ and $7^{\text {th }}$ grade $)$ 
students, including further assessment of the nature of verbal sexual harassment as well as selected characteristics of the victims of verbal sexual harassment. Additionally, this research seeks to assess the effectiveness of one school-based violence reduction program, Shifting Boundaries, as implemented in the New York City School System in 2009-2010. Lastly, drawing on Connell's $(1987 ; 2005)$ postmodern feminist theory (Gender Order Theory) as well as Script (Sexual Script) Theory (see Gagnon \& Simon, 1973; Simon \& Gagnon, 1986), potential explanations for the prevalence and pervasiveness of verbal sexual harassment are made. 


\section{CHAPTER II}

\section{REVIEW OF THE LITERATURE}

\section{Sexual Harassment}

The expansive literature on sexual harassment has primarily focused on the pervasiveness, occurrences, and consequences of the entire range of sexual harassment behaviors, neglecting the important differences between physical and verbal harassment. More conceptual weight in academic, popular culture, and policy discussions has been given to physical sexual harassment than verbal sexual harassment, as actions are perceived to be more consequential than "just words." While this scholarship has not denied that verbal sexual harassment is consequential (Gruber \& Fineran, 2008; Hand \& Sanchez, 2000; McMaster et al., 2002), physical sexual assault has been the primary focus of prior sexual harassment research. And, while some would discount verbal sexual harassment as not harmful, research findings suggest that it can be as life-altering as physical sexual violence and harassment (Exner-Cortens et al., 2013; Işik \& Kulakaç, 2015; Parker \& Asher, 1987; Rhinehart et al., 2014).

Similarly, past research on sexual harassment among adolescents has primarily focused on the combined effect of verbal and physical sexual harassment, often in conjunction with other forms of masculine and aggressive behaviors (Espelage et al., 2015; Gruber \& Fineran, 2008; Hand \& Sanchez, 2000; Miller, 2008; Pellegrini, 2001; Wei \& Chen, 2012). This research typically personifies females as victims, and males as perpetrators (Espelage et al., 2012; Fineran et al., 2009; Gruber \& 
Fineran, 2008), therefore reinforcing gendered norms. Studies have further shown that early sexual harassment behaviors continue into dating (Chiodo et al., 2009; Espelage \& Holt, 2007; Stein, 1995; Wolfe et al., 1998) where victims and perpetrators of sexual harassment will continue to be either victims or perpetrators of sexual harassment in adolescent or adult dating contexts (McMaster et al., 2002; Peterson \& Hyde, 2009).

Despite the focus of most research on physical sexual harassment, AAUW's (2011) study found that verbal sexual harassment incidents were more prominent than physical sexual harassment among students. Wise and Stanley (1987) identified verbal sexual harassment as a "dripping tap", which involves sexual comments and jokes that occur so frequently they are considered normal and mundane behavior. Other studies have also recognized that this behavior is normal and that children do accept it as part of their everyday culture (deLara, 2008; Hlavka, 2014; Lichty \& Campbell, 2012; Robinson, 2005). Students have also resorted to neutralizing verbal sexual harassment by making statements such as "it was a joke" or "we are just playing around" (Lichty \& Campbell, 2012). When students neutralize or justify verbal sexual harassment, it reduces the ability of young people to define or recognize harassment as victimization.

One study that examined only verbal sexual harassment victimization and its effect on Turkish adolescent girls (Işik \& Kulakaç, 2015) found boys were overwhelmingly the perpetrators and girls were the primary recipients of such behaviors. The majority of the female students did not believe the harassment could be stopped by authoritative figures; therefore, they did not seek help for it to be stopped. The consequence of believing nothing could or would be done led many girls to change or 
even restrict various aspects of their lifestyle to avoid verbal sexual abuse (Işik \& Kulakaç, 2015).

Recently, Rolfe and Schroeder (2017) examined verbal sexual harassment victimization and perpetration by gender and dating experience among sixth and seventh graders. They found that boys overall experienced more verbal sexual harassment than girls. And students with prior dating experience have increased odds of being a victim of verbal sexual harassment by their peers or a perpetrator of verbal sexual harassment towards their peers. Their findings further suggested that middle school students are engaging in a form of sexual harassment at a much earlier age than previously recognized by educators and policymakers.

\section{Prevalence of Sexual Harassment in Schools}

The prevalence of sexual harassment in our educational institutions has been documented in a number of studies. (Benson \& Thomson, 1982; Reilly et al., 1986; AAUW, 1993, 2001, 2011; Corbett, 1993; McMaster et al., 2002; Hill \& Silva, 2005; Gruber \& Fineran, 2007; Cantor et al., 2015; Wolff et al., 2017; Crittenden et al., 2018 ; Klein \& Martin, 2019). And, while much of the research has concentrated on college and university students and students from the $8^{\text {th }}$ to the $12^{\text {th }}$ grade, research suggests adolescents are experiencing sexual harassment at a much younger age. As early as 2001, an AAUW study found that more than a third of all high school students had experienced sexual harassment before entering the sixth grade. Another study found that $28 \%$ of the girls and $34 \%$ of the boys in grades 5-8 acknowledged being perpetrators of sexual harassment toward their peers (Espelage et al., 2012). Overall, research has found that 
sexual harassment starts at a young age and escalates during middle school into high school (Espelage \& Holt, 2007; Halpern et al., 2009; McMaster et al., 2002; Pellegrini, 2001). For example, Hand and Sanchez (2000) found the frequency of sexual harassment increased with grade level: $55 \%$ of eight and ninth graders experienced physical sexual harassment compared to $61 \%$ of tenth and eleventh graders.

Some studies have identified factors related to the prevalence of sexual harassment within our schools. For example, one study found that nearly every student $(96 \%)$ reported they had witnessed all forms of sexual harassment occurring in the open spaces (i.e., hallways, classrooms, and cafeterias) of their schools (Lichty \& Campbell, 2012). Such areas have been identified by other studies to be problematic because they lack supervision from schoolteachers and staff (AAUW 1993, 2001; Trigg \& Wittenstrom,1996). Despite the lack of supervision in such areas, Charmaraman et al. (2013) found that middle school personnel believed sexual harassment only occurred between adults and/or adults toward students. Thus, faculty and staff did not actively participate in preventing peer-to-peer harassment, especially verbal sexual harassment.

\section{Age and Sexual Harassment Victimization}

Research on the age of students and sexual harassment has primarily focused on student in the 8 th through 12 th grades. Studying students at this age makes logical sense

due to emotional, psychological, and physiological development and interest in exploring the dating culture and sex that occurs at this stage of their development. Age was a contributing factor for experiences with sexual harassment for both males and females (McMaster et al., 2002; Peterson \& Hyde, 2009). Age was, however, especially 
significant for females largely due to the differential degrees of sexual development among middle school- and high school-aged girls (McMaster et al., 2002; Peterson \& Hyde, 2009; Polce-Lynch et al., 2001).

\section{Race and Sexual Harassment Victimization}

Research is scant concerning the relationship between experience with sexual harassment and racial and economic differences among youth. However, within the few studies that have explored this relationship, most of the findings suggest that Caucasian students are less effected by sexual harassment than racial and ethnic minority students (Alleyne-Green et al., 2012). It also appears that the collateral consequences of sexual harassment victimization appear to be far greater for minorities than their Caucasian peers. For example, minority students are more likely to stop participating in extracurricular activities, have problems with concentrating on their studies, and change their routes to and from school in reaction to sexual harassment victimization. For some, requesting to change school venues might be their only hope of escaping further sexual harassment victimization (AAUW, 2011).

Goldstein et al. (2007) examined peer sexual harassment among African American and European American adolescents. They found that African Americans and females reported a higher level of victimization than males and Caucasian students. Another, and more recent study, found race to be a significant indicator for physical sexual harassment, especially for African American girls (Espelage et al., 2016). Although limited, other studies have come to different conclusions. For example, Espelage and Holt (2007) found that sexual harassment victimization by peers did not 
vary significantly by race. Obviously, further research is necessary to determine the precise relationship.

\section{Effects of Exposure to Anti-Violence Educational Programs}

According to a national survey published in 2011, 65 percent of students in the United States between the ages of 5 and 17 were exposed to a school-based violence prevention program. Of those, 21 percent participated in some form of a sexual assault prevention program (Finkelhor et al., 2014).

In one of the earliest known longitudinal studies on dating violence programming, Foshee and her colleagues (1998) measured the impact of a violence prevention program (Safe Dates) on perpetration and victimization behavior for participating and nonparticipating eighth and ninth grade students in a rural community. Follow-ups started as early as a month after the intervention was introduced to the students, with a 1-year positive effect on dating violence and conflict management skills (Foshee et al., 2000). Four years later, when students who participated were compared to non-participants, the program effects were still found to be positive for the reduction of reported dating violence perpetration and victimization (Foshee et al., 2004). The Foshee et al.'s (2004), study is one of only a few studies that have addressed sexual harassment among middle school students. Based on such findings, scholars have suggested that sexual harassment programs should be implemented as early as middle school (Espelage \& Holt, 2007;

McMaster et al., 2002; Wolitzky-Taylor et al., 2008) or even earlier - elementary school (Callahan et al., 2003; Eaton et al., 2010, 2012) to prevent sexual harassment, dating violence, and other forms of sexual violence. 
Other studies assessing the effectiveness of violence reduction programs have generally found that exposure to these programs was followed by a reduction in overall victimization and offending (Anderson \& Whinston, 2005; DeGue et al., 2014; Espelage et al., 2013; Foshee et al., 1998, 2000, 2004; Foshee \& Reyes, 2009; Hickman et al., 2004; Lundgren \& Amin, 2015; Taylor et al., 2010a,b; Taylor et al., 2013; Wolfe et al., 2009).

Two meta-analyses have been conducted on general school-based violence prevention programs. In 2008, Park-Higgerson and her colleagues assessed a total of 26 randomized controlled trials (RCT) for programs directed at students in grades 1-11. The authors found no significant difference between exposure and non-exposure to the violence prevention programming in the reduction of aggression and violence. However, there was a slight positive effect for intervention programs that relied on a non-theorybased approach and used "intervention specialists" who targeted older children considered to be at-risk youth.

The other and more recent meta-analysis (see De La Rue et al., 2017) examined 23 studies on teen dating violence programs with experimental and control groups. Among the studies, 13 were found to have an overall positive effect on dating violence knowledge for students in the treatment group compared to the control group at the posttest and follow-up, regardless of how the program was delivered. Unfortunately, knowledge about dating violence diminished over time, especially at follow-up. This study echoes previous studies (Fellmeth et al., 2013; Ting, 2009) on school-based dating violence prevention programs which found a short-term positive effect on participants' knowledge and attitudes regarding dating violence. The knowledge and attitudes, 
however, have limited long-term effects as they dissipated over time. Such findings are not a surprise. Groups such as the World Health Organization (2010) stated that actual behavior will probably not change despite efforts to improve knowledge and attitudes about dating violence among this population. Researchers also agree that dating violence prevention programs have only incrementally improved adolescents' knowledge and attitudes about dating violence, but the breadth and depth of programming have yet to be determined in reducing violence among early adolescents, high schoolers, and beyond.

Regardless of the short-term effectiveness of various anti-violence programs for sexual harassment, sexual assault/rape, dating violence, and/or family/domestic violence, findings concerning the longevity of the positive effects of the programs are inconsistent. Methodological issues have been raised with respect to many of the program analyses. For example, a review of dating violence prevention programs found two issues. First, most studies were exploratory in nature, and had less-than-rigorous research designs that could explain the strength and the positive effect the program had on its participants (Cornelius \& Resseguie, 2007; Meyer \& Stein, 2004). The second problem lies with the age of the students as subjects. Most studies have focused on high school students yet, scholars have acknowledged the prevalence of sexual harassment among students to begin as early as the fifth grade (Espelage et al., 2012; Wolitzky-Taylor et al., 2008). Consequently, the findings may not be generalizable due to the nature of the samples used. Lastly, most school-based anti-violence programs (AVP) are siloed into specific types of violence (e.g., bullying, sexual harassment, sexual assault, dating violence, etc.) (Leff et al., 2001), rather than, taking a broader approach reflecting understanding of the complexities and overlap shared between the various forms in terms of both perpetration 
and victimization. Additionally, many of the programs assessed attitude rather than behavioral change, varied widely in what constituted "participation" in a school-based sexual violence program and included a wide range of "programs" from one-day programs with structured curriculum to informational pamphlets distributed to students to take home to their parents (Finkelhor et al., 2014).

\section{Theoretical Framework}

\section{Gender Order Theory and Hegemonic Masculinity}

One of the theories that frame the current study is Connell's (1987) gender order theory. Of particular interest is Connell's theoretical concept of hegemonic masculinity, which, as one author noted, "is clearly the most popular and influential element of Connell's theory of masculinity" (Wedgwood, 2009, p. 335). As a sociological concept, hegemonic masculinity derives from Gramsci's (1971) theory of cultural hegemony. While initially used to explain the stability of class relations, hegemony was later used to describe gender relations. Hegemonic Masculinity refers to a position of dominance that derives from shared beliefs and norms rather than force. Women as well as men benefit from this "cultural ideal" of manhood as women are rewarded with their "attentions and efforts to replicate this ideal in their male relatives and associates" (Jewkes et al., 2015, p. 97).

Hegemonic Masculinity as initially conceived by Connell (1987), is based on the presumption that socio-structural factors favor men who gain benefit from their positions in society. The provision of this opportunity and access does not necessarily mean they will take advantage of the social structural differential. They can choose whether or not to 
"occupy oppressive positions vis-à-vis women and other men or to resist them" (Jewkes et al., 2015, p. 2). And, while the choices may be very limited, there are, nonetheless, exist options to assumptions of a position that creates asymmetric relationships between men and women and men and "other" men.

This perspective recognizes the significance of groups in forming and defining norms and other forms of expectations as well as rewards. As such, the expectations of ideal manhood are not consistent across all social groups. These ideal manhood expectations additionally determine interrelationships between groups as well as the distribution and access to scarce resource between groups (Hearn et al., 2012).

As described by Jewkes (2015):

Raewyn Connell's concept of hegemonic masculinity (Connell, 1987) serves as an analytical instrument to identify those attitudes and practices among men that perpetuate gender inequality, involving both men's domination over women and the power of some men over others (often minority groups of men).

Following a review of works discussing Hegemonic Masculinity, the general description of this concept was the following:

[A] set of values, established by men in power that functions to include and exclude, and to organize society in gender unequal ways. It combines several features: a hierarchy of masculinities, differential access among men to power (over women and other men), and the interplay between men's identity, men's ideals, interactions, power, and patriarchy (Jewkes \& Morrell, 2012, p. 40).

As noted previously, the definitions of sexual misconduct have varied across sexual harassment research. There is, however, a general agreement that the central component of these acts is not just sexual in nature but is, instead, based on power differentials and control (Uggen \& Blackstone, 2004). Central to the commission of these acts is the nature of socially structured sex, gender, and sexual relationships. Behaviors, attitudes, expectations and beliefs follow from Hegemonic Masculinity and the 
asymmetric relationships it creates between men and women with men having the greater "power". These traditional male and female roles create "power" differentials that determine an individual's opportunities and rewards within society. While power is not absolute, it is however, a relationship that structures our social interactions with one another, especially between men and women (Messerschmidt, 2018).

Hegemonic Masculinity therefore results in socialization of men and boys to seek authoritative power and dominance over girls and females (Connell \& Messerschmidt, 2005). To facilitate and embrace this perspective, boys are rewarded by displaying aggression towards those perceived to be less masculine than others, which are primarily females and feminine boys (Messerschmidt, 2000). Men in general, who are also visibly heterosexual (especially White men), are considered more masculine and therefore able to achieve more economic success (Connell \& Messerschmidt, 2005; Lorber, 1994). While masculinity might be easier for some men than others, it does not happen in a vacuum. Achieving masculinity is difficult and rarely ever achieved in totality (Connell $\&$ Messerschmidt, 2005). However, these challenges do not deter various subcultures from defining masculinity as a valued goal and, in some instances, to redefine masculinity and the "route to completion" to be consistent with resources accessible to members of the specific subculture. Simply put, achieving masculinity is completely different for inner city Black men (Archer, 2004), the LGTBQ community (Ocampo, 2016), and high-tech company workers compared to factory workers (Cooper, 2000), and religious men who practice abstinence before marriage (Wilkins, 2008). The need for subcultures to redefine masculinity based on subcultural resources illustrates how 
significantly important our society views masculinity as a means of success (Connell \& Messerschmidt, 2005; Risman, 2004; Schrock \& Schwalbe, 2009).

\section{Social Script Theory}

The expectations, beliefs and values consistent with Hegemonic Masculinity become transferred through their influence on the development of social scripts. Social script theory derives from the work of Berger and Luckman (1966) and their conceptualization of the "social construct of reality". This perspective posited that individual and, therefore, collective realities are constructed through externalization, internalization and objectification. The works of Goffman $(1959,1967,1974)$ characterized human interaction as scripted in that individuals play roles based on social expectations, values and norms. "Social script theory articulates those roles as social functions and they do so within the context of a situation as witnessed by others" with associated rewards or punishment depending on the degree of individual adherence to the scripted social roles (St. Clair et al., 2005, p. 2). Social scripts are not innate, but are both simple and complex, verbal and nonverbal, culture/subculture specific, learned through interaction with others and reinforced through reward and sanctions (Meng, 2008).

Building upon this perspective, Gagnon and Simon (1973) proposed a sexual script framework, applicable to sexual behavior, that involves three interrelated factors. First, cultural scripts refer to the broader framework of normative sexual behavior, which is often reinforced by institutions (e.g., marriage laws and formal sex education curriculum). Second, interpersonal scripts are where individuals determine how to navigate and negotiate sexual interactions. Finally, intrapsychic scripts refer to the 
internalized norms in which individuals believe and understand what their sexual experiences might and should be like. Thus, sexual scripts, while different for men and women, are crucial to the negotiation process of establishing boundaries and consent. These scripts are then "written" within the context of Hegemonic Masculinity and the consequent power differentials that it creates between men and women. By the time students have reached middle school, they have already been exposed to an array of cultural messages about sexuality and therefore begin to explore romantic relationships within the context of shared cultural understandings of sexual scripts.

Prior research has shown these sexual scripts to be associated with sexual violence among adults (Kimmel, 2007). For instance, the misconception of "women who say 'no' are just playing hard to get" is an influential sexual script for men that influences their approach to sex and dating (Anderson et al., 2004; Kimmel, 2007) and can contribute to sexual aggression (Muehlenhard, 2011). Stinson (2010) further argued that individuals who frequently participate in the dating "hook up" culture are at an increased risk of sexual victimization as well. Although middle school students may not be participating fully in the "hook up" culture, they do participate in the culture of boyfriend/girlfriend dialogue and associated sexual scripts. Thus, the perception of how many boyfriends or girlfriends an individual has had likely influences on whether or not they are involved in sexual harassment as either a victim or perpetrator (Espelage \& Holt, 2007; Rolfe \& Schroeder, 2017).

Our school system is and has been a central location for children and adolescents to explore, learn, and embrace gender and sexuality norms (Paechter, 2007; Pascoe, 2005) through the lens of hegemonic masculinity (Connell \& Messerschmidt, 2005). 
Hegemonic masculinity is further reinforced by schools which have gender-based policies (masculine vs. feminine), the curriculum, and how it is taught by teachers (i.e., boys are called upon more than girls), gender specific dress codes and sports, and differing disciplinary actions by school officials based on gender (Connell, 1996). Schools teach students more than just math, reading and writing, but also serve as the "location" to teach and perpetuate gender roles based on the heterosexual norms of our society (Morris, 2012; Risman, 2004).

The hegemonic masculinity perspective prescribes that boys are taught to be tough, aggressive, and dominant, with the consequential emphasis and reward of aggression toward others, primarily females and boys who are perceived to be less masculine than the norm (Messerschmidt, 2000). Related to this, prior research shows girls are victimized by sexual harassment more often than boys (AAUW, 1993, 2001, 2011; Fineran \& Bennett, 1999) and boys are primarily the perpetrators of sexual harassment (AAUW, 1993, 2001, 2011; Hand \& Sanchez, 2000; McMaster et al., 2002).

However, males also engage in same-sex sexual harassment as a means of establishing a social hierarchy based on masculine dominance (Espelage et al., 2018; Ferguson, 2000; Kimmel, 1996; Oransky \& Marecek, 2009). For example, the term "gay" and "fag" are insults used by boys to emasculate other boys (AAUW, 2011; Espelage et al., 2018). Regardless of gender, research has shown that most students encountered unwanted sexual comments, jokes and gestures, and sexual rumors being spread about them (AAUW, 2011; Taylor et al., 2010a,b). 


\section{The Current Study}

As noted previously, the current study seeks to fill the void in research on verbal sexual harassment, verbal sexual harassment among $6^{\text {th }}$ and $7^{\text {th }}$ grade students, and to explore the potential effect of an intervention program designed to reduce sexual harassment among adolescents in a large urban area. The study also seeks to identify some of the individual-level factors that differentiate victims of verbal sexual harassment from non-victims. Specifically, the study will explore the potential differential effects of these factors when variations in same-gender and cross-gender verbal sexual harassment victimization are examined. Lastly, the findings will be interpreted with respect to Hegemonic Masculinity as a theoretical concept and sex scripts within the framework of Social Script Theory.

The current analysis is based on secondary self-report data collected during the 2009-2010 academic year from sixth and seventh grade students who were enrolled in New York City middle-schools, when the randomized controlled experiment was conducted. In accordance with the theoretical predictions (hegemonic masculinity and sex scripts) and prior research findings, the following hypotheses are formulated:

Hypothesis 1: When compared to male students, female students will be more likely to report at post-test verbal sexual harassment victimization.

Hypothesis 2: A positive relationship is anticipated between pre-test verbal sexual harassment victimization and post-test verbal sexual harassment victimization.

Hypothesis 3: Students enrolled in the $7^{\text {th }}$ grade will likely report more verbal sexual harassment victimization than $6^{\text {th }}$ grade students.

Hypothesis 4: Students with dating experience will report verbal sexual harassment victimization more often than students with no dating experience. 
Hypothesis 5: The incidence of verbal sexual harassment victimization is expected to be greater for non-white students compared to white students.

Hypothesis 6: Students who reported prior participation in an anti-violence program before the pre-test will report at post-test lower levels of verbal sexual harassment victimization than students who did not report participation in an antiviolence educational program before the current experiment started.

Hypothesis 7: Students in the experimental group (those exposed to the violence prevention program) are expected to report a lower level of verbal sexual harassment victimization than students in the control group (those not exposed to the violence prevention program). 


\section{CHAPTER III}

\section{METHODOLOGY}

\section{Data and Sampling Procedures}

The current study seeks to contribute to knowledge about verbal sexual harassment and school violence reduction programs through the analysis of secondary data made available by the Inter-university Consortium for Political and Social Research (ICPSR). The data source comes from the study entitled Experimental Evaluation of a Youth Dating Violence Prevention Program in New York City Middle Schools, 2009-2010 (ICPSR 32901; see Taylor et al., 2012). The Youth Dating Violence Prevention Program sought to increase middle school students' knowledge of interpersonal violence, domestic violence and harassment, and of the laws related to violence issues. The program also was intended to familiarize students with resources for help and to improve their ability to decipher between acceptable and not acceptable behavior when interacting with others or witnessing violence.

In order to accomplish this, Taylor et al. (2012) administered the Shifting Boundaries prevention program, which had two components - a classroom-based intervention and a school building-based intervention. The classroom-based intervention program was an adaption of the Law and Justice Treatment (LJT) program used in Cleveland, Ohio (Taylor et al., 2008). To further develop and tailor this program to the needs and conditions of NYC students, Taylor and colleagues (2012) relied on input from 
the central office of the New York City Department of Education.

While these two programs are similar in nature, and both studies used randomized control trial techniques, Shifting Boundaries focused heavily on the consequences of domestic violence and harassment perpetration and on the state and federal laws pertaining to domestic violence, harassment, and sexual harassment. Additionally, the classroom-based program addressed issues related to effective communication in interpersonal relationships and discussed the role of bystanders (i.e., the importance of intervening when witnessing interpersonal violence). In all, the classroom curriculum for Shifting Boundaries included six lessons and was administered over a six to ten-week period to students selected to be part of two out of three experimental groups (i.e., exposure to treatment in the classroom only; exposure to treatment in the school building only; and, exposure to treatment in both the classroom and in the school building).

The school building intervention program relied on a number of sources. Many program features were based on recommendations made by teen dating violence experts (see NIJ and NIH, Dec. 4-5, 2007 meeting). Overall, there were four school buildinglevel interventions used during the same six to ten-week period as the classroom-based interventions. They were as follows: "1) revised school protocols for identifying and responding to domestic violence and harassment, 2) the introduction of school-based restraining orders (Respecting Boundaries Agreement), and 3) the placement of posters in school buildings to increase the awareness and reporting of domestic violence and harassment" (see Taylor et al., 2012, p. 27). The fourth component was working with students and school personnel to identify and develop "hotspot" maps, which are areas throughout the school that would encourage various forms of violence due to the lack of 
adult supervision. As a result of these "hotspot" maps, during the experiment, there was a greater presence of school personnel in these areas in order to promote safety and discourage violence. However, it should be noted, Taylor and colleagues were unable to specifically identify which one, if any, of these four building-level interventions had an effect on reducing domestic violence and sexual harassment (Taylor et al., 2012).

Taylor et al. (2012) used a randomized controlled trial to administer their schoolbased intervention Shifting Boundaries to sixth graders $(\mathrm{n}=1,266)$ and seventh graders (n $=1,388)$ throughout a total of 117 classrooms in 30 New York City middle schools. Both schools and classrooms were randomly chosen using a stratified sampling procedure, with students being placed into one of four conditions: 1) a classroom-based intervention, 2) a school-wide (building) intervention, 3) both classroom and school-wide interventions, or 4) no treatment. These four conditions created three experimental groups and one control group. It should be noted that Taylor and his colleagues (2012) did not provide information on how the stratified sampling technique was applied to their sample.

While Taylor and colleagues collected data for their study using both survey and interview techniques, the current study solely relies on data collected from the self-report surveys. The data was collected using optical scanning (paper and pencil surveys) techniques and distributed at three different times throughout the 2009-2010 academic year: 1) pre-test: before antiviolent programming was administered to the students, 2) post-test: immediately after treatment, 3) final post-test: five to six months after treatment. 
Although Taylor et al.’s (2012) study focused on dating violence and sexual harassment and the effectiveness of the anti-violence treatment program, the current research examines immediate post-test data for verbal sexual harassment (VSH) victimization, while taking into account baseline information on VSH victimization as a means of assessing program effectiveness as well as the nature of verbal sexual harassment. The overall response rate in the Taylor et al.'s study was 93\%, which means that 2,655 students participated in all three phases of the data collection process. Despite having a high response rate, the data had one deficiency; many of the key variables used in this study had a large number of missing values, which reduced both the pre- and immediate post-test working sample. There are several possible explanations for missing responses to key variables: 1) survey fatigue (i.e., the survey included 254 questionnaire items; 2) while customary to place demographic questions on the last page of the survey, many of these questions went unanswered due to the lengthy questionnaire, and 3) limited time - students were given only one class period (approximately 40 minutes) to start and complete the survey. Only cases with complete information were used in this analysis. This resulted in a total of 1,109 cases in the overall study sample.

In sum, the current analysis uses cases with complete information on the variables of interest $(\mathrm{N}=1,109)$, as well as two subsample groups. The first subsample separates the overall study sample by gender ( $n=499$ males; $n=610$ girls). The second subsample identified cases through propensity score matching, which was used to specifically create a matched subsample. That is, a subsample of 339 students in the experimental group and 
a subsample of 339 students in the control group. They were matched on the relevant independent variables (gender, grade (i.e., age), race, dating experience, and pretreatment exposure to an educational program on sexual violence).

\section{Measures}

\section{Dependent Variable}

Verbal sexual harassment victimization at the immediate post-test (T2). Because the current study is concerned only with verbal sexual harassment victimization, seven questions that clearly indicated hands-off verbal sexual harassment offending behavior were selected from the 14-item sexual harassment scale used in prior research (see AAUW 1993, 2001; Taylor et al., 2012). Initially, a composite measure was created using responses from seven questionnaire items, which have been duplicated to record one's victimization by a male peer and then by a female peer. Specifically, respondents were asked "Has any girl or boy done any of the following TO YOU at school or during a school-sponsored activity when you did not want them to since the last survey?” 1) Made sexual comments, jokes, gestures, or looks about/to you; 2) Showed, gave, or left

you sexual pictures, photographs, messages, or notes; 3) Wrote sexual messages or graffiti about you on bathroom walls, in locker rooms, or other places; 4) Spread sexual rumors about you; 5) Said you were gay or a lesbian, as an insult; 6) Spied on you as you dressed or showered at school; 7) "Flashed" or "mooned" you? (see Appendix A). The response categories were as follow: "How many times did a male do this to you since you last took this survey?" Initial responses have been recoded as zero, if the respondent acknowledged no victimization and 1, if the initial response indicated he/she experienced 
a particular type of VSH victimization at least once. The index created based on responses to 14 questionnaire items appeared to be reliable $(\alpha=.770)$. Due to the fact that half of the respondents (46\%) indicated they had not been victimized by any of their peers and in order to create a better representation of the data, a categorical-level variable was created. The dependent variable was coded zero, (if the respondent did not experience any type of VSH victimization), 1, (if he/she acknowledged at least one type of VSH victimization by peers of the opposite sex only), 2 (VSH victimization by peers of the same sex only), and 3 (VSH victimization by both male and female peers).

\section{Independent Variables}

Based on the literature that was outlined in the previous chapter, seven independent variables, described below, will be used in the statistical analyses.

\section{Exposure to the School Violence Prevention Program (Treatment}

“Experimental" Group). Respondents initially included in any of the three treatment groups (classroom, school-based, both classroom and school-based) have been coded as 1 and those in the control group were coded as 0.

Verbal sexual harassment victimization at the pre-test (T1). A summative scale was created based on the respondents' answers to the 7 questions identified as VSH in the baseline survey (see dependent variable). These questions are similar to those at the post-test, but their attributes are different. The respondents were asked, "Has anyone ever done any of the following TO YOU at school or during a school-sponsored activity when you did not want them to?" Response choices were "No", "Yes, male(s), and "Yes, female(s) (see Appendix B). Respondents who acknowledged victimization by males or 
females to any of the seven questions were coded as 1, and zero otherwise. A summative scale was created ranging in value from 0 to 7 . The reliability value for this variable was found to be acceptable with a Cronbach Alpha score of .765 .

Dating experience. The dating experience of respondents is measured with a single question, "Have you ever been in a boyfriend/girlfriend dating relationship that lasted more than one week?" Responses were coded as no $=0$ and yes $=1$.

Prior anti-violence programming. This dichotomous variable differentiates respondents who had participated in an antiviolence training or education program prior to the implementation of the Shifting Boundaries program (coded as 1) from those who did not (coded as 0 ). Respondents were asked, "Have you ever attended an educational program about sexual harassment, sexual assault/rape, dating violence, and/or family/domestic violence?"

Gender. This dichotomous variable is coded 1 if the respondent was female and zero if the respondent was male.

Grade (age). The student's grade in school has been used as a proxy for age. The age variable had a substantial number of missing cases in the original sample (39.8\%) and included three age categories: 11 years old and younger, 12 years old, and 13 years old and older. The variable used here differentiated respondents in the $7^{\text {th }}$ grade (coded as 1) from younger respondents enrolled in the $6^{\text {th }}$ grade (coded as 0 ). The variable is moderately correlated with the variable age $(\mathrm{r}=.63 ; p<.05)$.

Race. This dichotomous variable is coded 1 , if the responded selected "white" when asked "what is your race?" and zero otherwise. The reference category includes respondents who identified as American Indian or Alaska Native, Asian, Black or African 
American, Native Hawaiian or Other Pacific Islander, Multiracial, and those who refused to answer the question.

\section{Analysis Plan}

The current study was conducted in four phases. The first phase was univariate analyses. Descriptive statistics were generated to assess variations in victimization and the selected predictors in the overall sample and in two subsamples differentiated by the respondent's gender. Taking into account the theoretical framework of the study, which predicts gender-based differences in behavior and social interactions, an examination of the frequency distributions also identified which type of VSH victimization was more common among girls and which was more common among boys. Additionally, intergroup comparisons would indicate if boys and girls included in the analysis are different or not in terms of race, age, dating experience, or prior VSH victimization, which have been identified in the literature as predictors of sexual victimization. These potential inter-group differences were important to identify as they might partially explain genderbased differences in victimization, if this was the case.

The second phase included a set of bivariate analyses. First, several paired samples $t$-tests were used to examine pre-test / post-test VSH differences in victimization reported by students in the experimental and control groups. Results are presented for the overall sample and for each subsample differentiated by gender. Second, bivariate correlations were generated to describe the strength of the relationships and direction of association among the variables used in this study. The correlation matrix was also used to determine whether multicollinearity was a potential problem. 
The third phase included multinomial logistic regressions that compared the effects of the selected predictors (exposure to the school program, VSH victimization at baseline (pre-test), prior dating experience, prior exposure to anti-violence programming, gender, age, and race) on post-treatment VSH victimization among students. This analysis includes six models, which are 1) VSH victimization by peers of the opposite sex versus non-victimization, 2) VSH victimization by peers of the same sex versus nonvictimization, 3) VSH victimization by both male/female peers versus non-victimization, 4) VSH victimization by peers of the opposite sex versus VSH victimization by same sex peers, 5) VSH victimization by peers of the same sex versus VSH victimization by male/female peers, and 6) VSH victimization by peers of the opposite sex versus VSH victimization by male/female peers).

The final phase included a statistical analysis meant to estimate the program's effectiveness, when two equivalent groups are created. Specifically, using propensityscore matching (PSM) methods, the potential differences between the experimental and the control group, which may obscure the program effects were controlled for. PSM attempts to reduce the treatment assignment bias, by creating a sample of units that received the treatment that is comparable on all observed covariates to a sample of units that did not receive the treatment (Rosembaum \& Rubin, 1983).

As mentioned previously, the experimental and the control groups were matched on gender, race, grade (i.e., age), dating experience, and pre-treatment exposure to an anti-violence educational program. Subsequent analyses (multinomial logistic regression) examined differences between victims and non-victims in the newly created subsample that mimics random assignment to the control and the experimental groups. This analysis 
produced an unbiased estimation of treatment effects and also served as a sensitivity analysis that verified the stability of the findings obtained in the prior analysis conducted on the initial sample $(\mathrm{N}=1,109)$. 


\title{
CHAPTER IV
}

\begin{abstract}
ANALYSIS
The analysis includes descriptive statistics, bivariate and multivariate analyses to assess factors related to verbal sexual harassment victimization as well as the effectiveness of school violence reduction programs in addressing verbal sexual harassment. The analysis was conducted in four parts, each part addressed one or more of the hypotheses identified previously. The first part of the analysis presents the characteristics of the overall sample and two subsamples, which are differentiated by the student's gender. The second part presents several paired samples $t$-tests to examine the differences in pre- and post-test outcomes of VSH victimization among students (overall sample and by gender) in the experimental group versus the control group. Also, using a correlation matrix, the strength of the relationship and direction of association of the covariates was determined. The third part presents six multinomial regression models that compare the selected predictors on post-treatment VSH victimization among adolescents. The final part presents the effectiveness of the treatment program to reduce VSH victimization among the sample of middle school students in this study.
\end{abstract}

\section{Descriptive Statistics}

Descriptive statistics (relative frequencies, means, standard deviations, range) are reported in Tables 1 and 2. Table 1 includes the descriptive statistics for the overall working sample $(\mathrm{N}=1,109)$. The descriptive analysis also examined the sample by gender and provides insight into cross-gender and same-sex gender verbal sexual harassment 
victimization and perpetration. Therefore, Figure 1 presents VSH victimization by gender after post-treatment. Table 2 reports the distribution of the outcome measures by gender ( $n=499$ boys; $n=610$ girls).

\section{Characteristics of the overall sample}

Table 1 contains reported verbal sexual harassment victimization among all respondents in the sample. Overall, approximately half (46\%) of the students reported no VSH victimization from their peers. The remaining students reported the following VSH victimization experiences: 25.3 percent reported VSH victimization from both their male and female peers; 17.1 percent reported VSH victimization by the opposite sex only; and11.5 percent reported VSH victimization from only same sex peers. As noted previously, the survey sample contained an experimental group (exposure to the school violence prevention program) and a control group (no exposure to the school violence prevention program). A total of $68 \%$ of the student respondents were part of the experimental group and $32 \%$ were part of the control group. In order to assess whether or not exposure to the school violence program affected verbal sexual harassment victimization, reported victimization of students in the two groups (experimental and control) were compared at pre-test (prior to implementation of the school program) and post-test (following implementation of the school program). An additional analysis was conducted to ensure that no confounding factors would interfere with further analysis of the program's effectiveness. It was found that the experimental (exposed to the program) and the control groups were similar in terms of gender structure, but differed significantly in terms of race, age, dating experience, and prior exposure to an anti-violence 
educational program. Additionally, the two groups were significantly different in terms of VSH victimization reported at baseline (exp. group: mean $=.67$; control group: mean $=$ $.56 t=3.524 ; p<.001)$. Due to these significant differences, propensity score matching was used and will be discussed further towards the end of this chapter.

A summative scale to measure verbal sexual harassment pre-and post-program exposure was created from the 14-item sexual harassment scale (See AAUW 1993). In all, 7-items were used to calculate VSH. The responses to the questions about verbal sexual harassment victimization were "yes" or "no". The affirmative responses were coded as " 1 " and the negative responses as " 0 ". The variable takes values from zero to 7. The mean value for the sample's reported baseline (i.e., pre-test) victimization was 1.56 $(S D=1.77)$. This indicates that, on average, students experienced less than two of the seven identified types of verbal sexual harassment prior to the Shifting Boundaries intervention program was introduced to them (see Appendix A).

In addition to reported verbal sexual harassment victimization, demographic and experiential characteristics of the students were also assessed with the goal of trying to determine whether or not they were related to the experience of verbal sexual harassment victimization. The sample had slightly more female students $(55 \%)$ than male students (45\%). The overwhelming majority (86\%) identified as non-white students. Age was determined by grade level ( $58 \%$ of the students reported being in the $7^{\text {th }}$ grade). The remainder $(42 \%)$ of the students reported being in the $6^{\text {th }}$ grade. Less than half $(41 \%)$ of the students reported having dating experience in their lifetime (i.e., relationship must have lasted a week or longer). About a third (34\%) of the sample also had prior 
experience with an anti-violence educational program prior to exposure to the current program.

\section{Table 1}

Descriptive Statistics for Verbal Sexual Harassment Victimization among Middle School Students

\begin{tabular}{|c|c|c|c|c|c|c|}
\hline Variables & Freq. (\%) & Mean & SD & Min & Max & $\alpha^{1}$ \\
\hline VSH Victimization (T2) & & & & 0 & 3 & .774 \\
\hline No Victimization & 46.0 & & & & & \\
\hline Victimization by opposite sex only & 17.1 & & & & & \\
\hline Victimization by same sex only & 11.5 & & & & & \\
\hline Victimization by males and females & 25.3 & & & & & \\
\hline \multicolumn{7}{|l|}{ Independent Variables } \\
\hline Treatment (experimental group) & & 0.68 & 0.465 & 0 & 1 & \\
\hline Reported VSH (T1) & & 1.56 & 1.770 & 0 & 7 & .765 \\
\hline Gender (female) & & 0.55 & 0.498 & 0 & 1 & \\
\hline Grade ( $7^{\text {th }}$ grade $)$ & & 0.58 & 0.494 & 0 & 1 & \\
\hline Race (white) & & 0.14 & 0.346 & 0 & 1 & \\
\hline Dating Experience & & 0.41 & 0.492 & 0 & 1 & \\
\hline Prior Anti-violence Programming & & 0.34 & 0.475 & 0 & 1 & \\
\hline
\end{tabular}

\section{Characteristics of subsamples differentiated by respondent's gender}

As noted previously, prior research has shown that gender and, therefore, gender norms play a significant role in sexual harassment. In order to assess the significance of gender in verbal sexual harassment victimization, reported incidents of verbal sexual harassment were separately assessed. As noted previously, the total sample $(1,109)$ contained $55 \%$ female and $45 \%$ male student respondents. Figure 1 contains the results of the assessment of the two subsamples based on gender, once the Shifting Boundaries intervention ended. As shown in Figure 1, nearly half of the female (46.6\%) and (45.3\%) male students reported no verbal sexual harassment victimization at post-test. Among those who reported victimization by verbal sexual harassment, approximately one in four female $(26.1 \%)$ and male $(24.4 \%)$ students reported VSH victimization by both male and 
female peers. Fewer female students (4.8\%) than male students (19.8\%) reported verbal sexual harassment by same-gender peers. Conversely, more female students (23\%) than male students (10.4\%) reported cross-gender VSH victimization. In sum, slightly more than half of the student respondents reported some type of verbal sexual harassment victimization from their peers. Female students were more likely than their male counterparts to report victimization by a peer of the opposite gender. Male students were more likely than female students to report victimization by a peer of the same gender.

\section{Figure 1}

Post-test victimization by gender

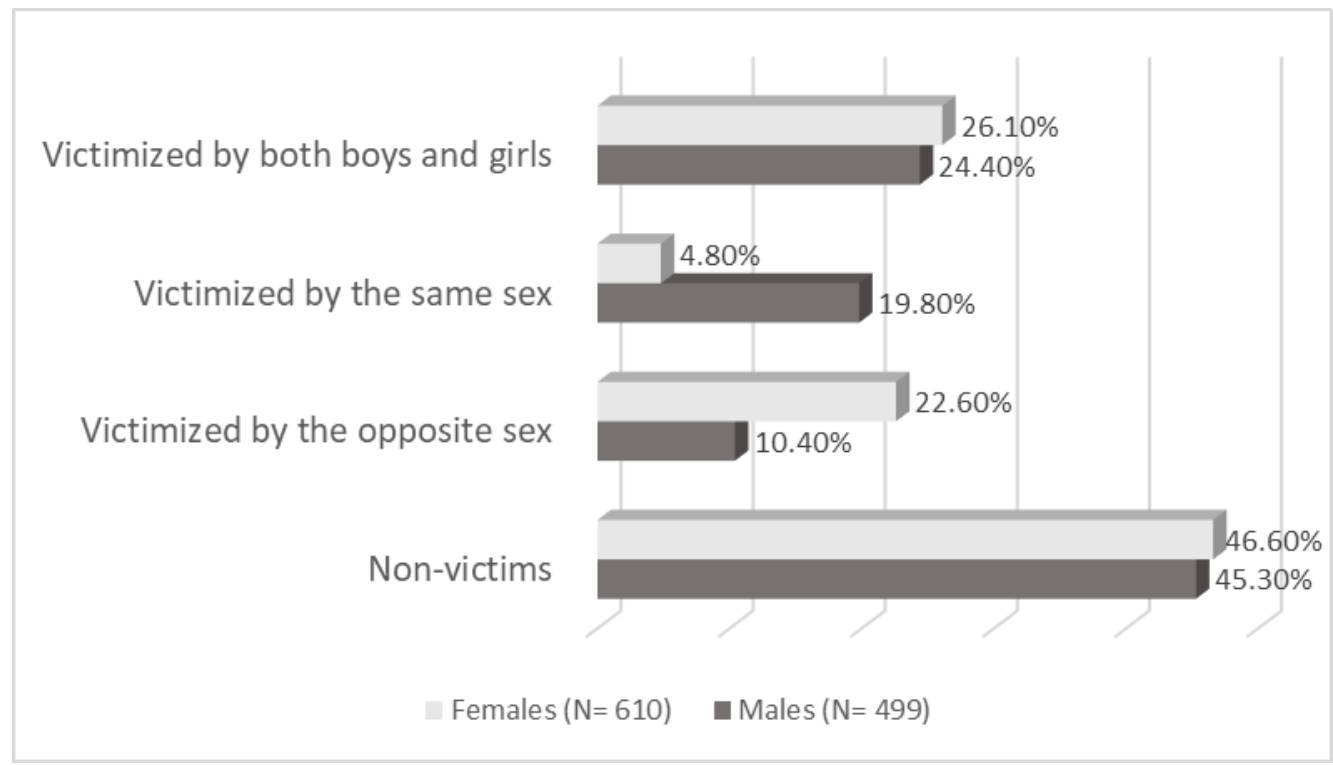


Table 2 contains reported verbal sexual harassment victimization for male and female respondents in the sample. Approximately half (45.3\%) of the boys and the girls $(46.6 \%)$ reported no VSH victimization from their peers. One in 10 boys reported VSH victimization by the opposite sex. The remaining male and female students reported the following VSH victimization experiences: $10.4 \%$ of the boys and $22.6 \%$ of the girls reported VSH victimization by the opposite sex only; $19.8 \%$ of the boys and $4.8 \%$ of the girls reported VSH victimization from only same sex peers; and $24.4 \%$ of the boys and $26.1 \%$ of the girls reported VSH victimization from both their male and female peers.

As noted previously, the survey sample contained an experimental group (exposure to the school violence prevention program) and a control group (no exposure to the school violence prevention program). The distribution of boys $(67 \%)$ and girls $(69 \%)$ in the experimental group and control (33\% boys; $31 \%$ girls) groups was fairly even. The mean value for boys reported baseline (i.e., pre-test) VSH victimization was $1.63(S D=$ 1.74). Girls reported slightly less $[1.50(S D=1.77)]$ than boys VSH victimization at pretest. As previously noted, having a mean victimization score lower than two, indicates that students (boys and girls) experienced, on average, less than two of the seven identified types of verbal sexual harassment prior to the Shifting Boundaries intervention program was introduced to them (see Appendix B). Although in both gender groups the majority of the respondents reported at post-test at least one instance of verbal sexual harassment (54.7\% of the boys and $53.4 \%$ of the girls), additional analyses (not shown) indicated that at the baseline interview, in each gender group, the proportion of respondents who acknowledged being sexually harassed verbally by their peers was much higher than had been recorded at post-test. Specifically, $66.3 \%$ of the boys and 
$60.8 \%$ of the girls reported being victims of at least one act of verbal sexual harassment before the program was implemented. Before the Shifting Boundaries intervention program was introduced, it was found that both boys and girls experienced, on average, comparable acts of verbal sexual victimization $(t=1.189, p=.235)$.

In addition to reported verbal sexual harassment victimization, demographic and experiential characteristics of each gender were also assessed with the goal of trying to determine whether or not they were related to the experience of verbal sexual harassment victimization. The overwhelming majority $(83 \%)$ of the boys and $(87 \%)$ of the girls identified as non-white students. Age was determined by grade level, $60 \%$ of the boys and $57 \%$ of the girls reported being in the $7^{\text {th }}$ grade. Boys $(45 \%)$ reported more dating experience in their lifetime than the girls (37\%). Girls (37\%) had a higher participation rate for prior anti-violence educational programming than the boys (31\%).

Results included in Table 2 also suggest that the two gender-based subsamples were comparable in several respects. Additional analyses (not included) indicated there were no significant inter-group differences in terms of exposure to treatment $\left(\chi^{2}=.620\right.$, NS), school grade $\left(\chi^{2}=.882\right.$, NS $)$, and ethnic composition $\left(\chi^{2}=2.310\right.$, NS $)$. However, dating experience was found to be significantly different between male and female students $\left(\chi^{2}=6.187, p<.05\right)$, as well as being previously exposed to an anti-violence program $\left(\chi^{2}=3.848, p=.05\right)$. Further analyses were also conducted to determine changes between comparison groups (experimental vs. control groups) after program exposure for the overall sample and by gender (see paired samples t-test). 
Table 2

Descriptive Statistics for Verbal Sexual Harassment Victimization by Gender

\begin{tabular}{|c|c|c|c|c|c|c|c|c|}
\hline \multirow[b]{2}{*}{ Variables } & \multicolumn{4}{|c|}{ Males $^{1}$} & \multicolumn{4}{|c|}{ Females $^{2}$} \\
\hline & $\begin{array}{c}\text { Freq. } \\
\%\end{array}$ & Mean & SD & Range & $\begin{array}{c}\text { Freq. } \\
\%\end{array}$ & Mean & SD & Range \\
\hline VSH Victimization (T2) & & & & $0-3$ & & & & $0-3$ \\
\hline No Victimization & 45.3 & & & & 46.6 & & & \\
\hline Victimization - opposite sex & 10.4 & & & & 22.6 & & & \\
\hline Victimization - same sex & 19.8 & & & & 4.8 & & & \\
\hline Victimization - both $\mathrm{M} / \mathrm{F}$ & 24.4 & & & & 26.1 & & & \\
\hline \multicolumn{9}{|l|}{ Independent Variables } \\
\hline Treatment (exp. group) & & 0.67 & 0.470 & $0-1$ & & 0.69 & 0.461 & $0-1$ \\
\hline Reported VSH (T1) & & 1.63 & 1.764 & $0-7$ & & 1.50 & 1.771 & $0-7$ \\
\hline Race (white) & & 0.17 & 0.364 & $0-1$ & & 0.13 & 0.331 & $0-1$ \\
\hline Grade $\left(7^{\text {th }}\right.$ grade $)$ & & 0.60 & 0.491 & $0-1$ & & 0.57 & 0.496 & $0-1$ \\
\hline Dating Experience & & 0.45 & 0.498 & $0-1$ & & 0.38 & 0.485 & $0-1$ \\
\hline Prior AVP & & 0.31 & 0.464 & $0-1$ & & 0.37 & 0.483 & $0-1$ \\
\hline
\end{tabular}

${ }^{1} \mathrm{n}=499$

${ }^{2} \mathrm{n}=610$

\section{Bivariate Analyses}

The current research included bivariate analyses for two reasons. First, paired samples $t$-tests were used to compare verbal sexual harassment for the experimental and control groups prior to (pre-test) and after respondents were exposed to the intervention program (post-test) within the overall sample and subsamples differentiated by gender. Second, a correlation matrix was used to examine the strength and direction of the relationships among the variables included in the analysis. It was also used to examine any potential multicollinearity issues that could negatively affect the multinomial regression models. The bivariate results are reported in Tables 3-5.

\section{Paired Sample t-tests for VSH Victimization: Post-test versus Pre-test}

In Table 3, the results of the bivariate analyses (paired samples $t$-tests) compare VSH victimization for the experimental and control groups prior to (pre-test) and after 
respondents were exposed to the intervention program (post-test) for both the overall sample and the two subsamples differentiated by gender.

The overall sample had 758 students in the experimental group and 351 students in the control group. The results show that both the experimental group and control group registered a significant decrease in the proportion of VSH victimization following program exposure. At pre-test, $67 \%$ of the students in the experimental group stated they had been victims of verbal sexual harassment. At post-test, there was a $10 \%$ decrease in the percentage of students in the experimental group (57\%) who reported VSH victimization $(t=-4.521, p<.001)$. Likewise, there was a similar $(9 \%)$ decrease in VSH victimization following program participation reported by the control group $(t=-3.088, p$ $<.001)$. Such a finding is contrary to expectations. The anticipated rate of reported incidents of verbal sexual harassment within the control group was anticipated to remain relatively consistent between the pre-test and post-test compared to the experimental group which had program exposure. In other words, the expectation was for a reduction from the pre-test to the post-test in reported VSH incidences for students in the experimental group (received treatment), not the control group (no treatment received).

Next, the two gender specific subsamples were assessed for pre- and post-test VSH victimization trends within both the experimental and control groups.

Male subsample. There were 335 male students in the experimental group and 164 male students in the control group. The subsample of boys showed a decrease in both the experimental and control groups for VSH victimization at post-test. The findings show the Shifting Boundaries program had a greater positive effect on boys in the experimental group, which registered a $13 \%$ decrease in VSH victimization from the pre- 
test to the post-test $(t=-4.147, p<.001)$ than boys in the control group. However, the overall sample showed that boys included in the control group, also reported a significantly lower level of victimization ( $8 \%$ decrease) from pre-test to post-test $(t=-$ $2.040, p<.05)$.

Female subsample. There were 423 female students in the experimental group and 187 female students in the control group. Like their male counterparts, the girls in the experimental group reported significantly lower levels of victimization at post-test $(6 \%$ decrease; $t=-2.336, p<.05)$. However, this decrease in victimization from the pre-test to the post-test for females in the experimental group was lower than the values reported by males in the experimental group. Additionally, contrary to expectations, there was a $10 \%$ decrease reported verbal sexual harassment victimization for the female control group between the pre-test and post-test, which was also found to be statistically significant $(t=$ $-2.312, p<.05)$.

Overall, there was a reduction in VSH victimization in the experimental group from the pre-test to the post-test for the entire sample as well as for both gender-based subsamples. Most notably, boys in the experimental group had the greatest reduction in reported VSH incidences from the pre-test to the post-test. However, the control group also showed a significant reduction in reported VSH victimization from the pre-test to the post-test for the entire sample as well as for both male and female students. 
Table 3

Bivariate Analysis - Paired Sample t-test for VSH Victimization Post-test versus Pre-test

\begin{tabular}{|c|c|c|c|c|c|c|c|c|c|}
\hline \multirow[b]{2}{*}{ Variables } & \multicolumn{3}{|c|}{ Overall $^{1}$} & \multicolumn{3}{|c|}{ Male $^{2}$} & \multicolumn{3}{|c|}{ Female $^{3}$} \\
\hline & $M$ & S.E. & $t$ & $M$ & S.E. & $t$ & $M$ & S.E. & $t$ \\
\hline \multicolumn{10}{|l|}{ Experimental } \\
\hline Post-test & .57 & .018 & $-4.521 * * *$ & .58 & .027 & $-4.147 * * *$ & .57 & .024 & $-2.336^{*}$ \\
\hline Pre-test & .67 & .017 & & .71 & .025 & & .63 & .024 & \\
\hline \multicolumn{10}{|l|}{ Control } \\
\hline Post-test & .47 & .027 & $-3.088 * *$ & .48 & .039 & $-2.040^{*}$ & .46 & .037 & $-2.312 *$ \\
\hline Pre-test & .56 & .027 & & .56 & .039 & & .56 & .036 & \\
\hline \multicolumn{10}{|c|}{${ }^{1}$ Overall Experimental $(\mathrm{n}=758) ;$ Control $(\mathrm{n}=351)$} \\
\hline${ }^{2}$ Male Experimental $(\mathrm{n}=$ & trol $(\mathrm{n}$ & $=164)$ & & & & & & & \\
\hline${ }^{3}$ Female Experimental ( & trol & $=187)$ & & & & & & & \\
\hline Note: $\dagger p<.10,{ }^{*} p<.05$ & & & & & & & & & \\
\hline
\end{tabular}

\section{Correlation Matrix - Overall Sample}

In preparation for the multivariate analysis that will explain the predictors and correlates of the various forms of verbal sexual harassment, a correlation matrix containing the dependent and independent variables was created for the total sample as well as the gender-based sub-samples. This was done for two reasons: 1) to understand whether there was a significant and positive relationship between the seven predictors and the dependent variable, and 2) to check for multicollinearity.

Table 4 presents the bivariate correlations for all the variables to be included in multivariate analyses. Out of the seven predictors, four of them were found to have significant and positive relationships with the dependent variable (verbal sexual harassment at the post-test). The strongest correlation was between VSH post-test and the VSH pre-test $(\mathrm{r}=.261, p<.01)$. When the effect of the other variables was not taken into account, students who reported VSH victimization at pre-test were more likely to report victimization after the program ended. 
The next strongest relationship was between VSH post-test and the adolescents' dating experience $(\mathrm{r}=.222, p<.01)$. That is, students with dating experience were more likely to experience VSH from their peers than students with no dating experience. Students who acknowledged exposure to an anti-violence educational program before exposure to the Shifting Boundaries program were significantly more likely $(\mathrm{r}=.104, p<$ $.01)$ to report VSH victimization after the Shifting Boundaries program ended. As anticipated by the prior analysis (see Table 3) and contrary to what was hypothesized, students in the experimental group were significantly more likely than those in the control group to report VSH victimization at the post-test, when the effect of other predictors was not considered $(\mathrm{r}=.100, p<.01)$. Gender, age, and race do not differentiate victims of verbal sexual harassment from non-victims at post-test. An examination of the correlation matrix suggested that multicollinearity was not going to be an issue in multivariate analyses (i.e., the highest bivariate correlation coefficient is .261). 
Table 4

Correlation Matrix - Overall Sample

\begin{tabular}{|c|c|c|c|c|c|c|c|c|}
\hline Variables & $\begin{array}{l}\text { VSH } \\
\text { (T2) }\end{array}$ & $\begin{array}{c}\text { Exp. } \\
\text { Group }\end{array}$ & $\begin{array}{l}\text { VSH } \\
\text { (T1) }\end{array}$ & $\begin{array}{l}\text { Prior } \\
\text { AVP }\end{array}$ & $\begin{array}{l}\text { Gender } \\
\text { (female) }\end{array}$ & $\begin{array}{c}\text { Dating } \\
\text { Experience }\end{array}$ & $\begin{array}{c}7^{\text {th }} \text { vs. } \\
6 \text { th }\end{array}$ & White \\
\hline VSH $\left(T^{1}{ }^{1}\right)$ & 1 & & & & & & & \\
\hline Exp. Group & $.100 * *$ & 1 & & & & & & \\
\hline VSH (T1) & $.261^{* *}$ & $.089 * *$ & 1 & & & & & \\
\hline Prior AVP & $.104 * *$ & $.092 * *$ & -.023 & 1 & & & & \\
\hline Gender (F) & -.013 & .024 & -.036 & $.059 *$ & 1 & & & \\
\hline Dating Exp. & $.222 * *$ & $.130 * *$ & $.215^{* *}$ & .034 & $-.075^{*}$ & 1 & & \\
\hline 7th vs 6th & .017 & $.092 * *$ & .032 & $.108 * *$ & -.028 & $.120 * *$ & 1 & \\
\hline White & .015 & $-.091 * *$ & -.055 & $.099 * *$ & -.046 & .004 & $.072 *$ & 1 \\
\hline $\begin{array}{l}{ }^{1} \text { VSH coded as } \\
\mathrm{T} 1=\text { pre-test VSH } \\
{ }^{*} \text { Correlation is } \mathrm{si} \\
{ }^{* *} \text { Correlation is } \\
\mathrm{n}=1,109\end{array}$ & $\begin{array}{l}\text { ization } \\
=\text { post- } \\
\text { cant at }\end{array}$ & $\begin{array}{l}\text { no victim } \\
\text { VSH } \\
.05 \text { level } \\
0.01 \text { level }\end{array}$ & $\begin{array}{l}\text { on }=0 \\
\text { ed). } \\
\text { iled) }\end{array}$ & & & & & \\
\hline
\end{tabular}

\section{Correlation Matrix by Gender}

Table 5 presents the inter-item bivariate correlations for each subsample differentiated by the respondent's gender. While both boys and girls who reported having dating experience were significantly more likely to also report post-test VSH victimization by peers, the association between dating experience and VSH victimization was stronger for female $(\mathrm{r}=.292, p<.01)$ than male adolescents $(\mathrm{r}=.137, p=.01)$. Alternatively, the relationship between prior participation in an anti-violence program and post-test victimization was twice as strong for boys $(\mathrm{r}=.145, p<.01)$ compared to 
girls $(\mathrm{r}=.073, N S)$. The treatment effect, however, was similar for both boys $(\mathrm{r}=.100, p$ $<.05)$ and girls $(\mathrm{r}=.099, p<.05)$. Additionally, both boys and girls in the experimental group were significantly more likely to report victimization than their respective counterparts (i.e., control group) who had not been exposed to the Shifting Boundaries program. Similarly, both boys $(\mathrm{r}=.245, p<.01)$ and girls $(\mathrm{r}=.274, p<.01)$ who reported VSH victimization at the baseline interview (pre-test) were significantly more likely to report VSH victimization at post-test.

Table 5

Correlation Matric by Gender

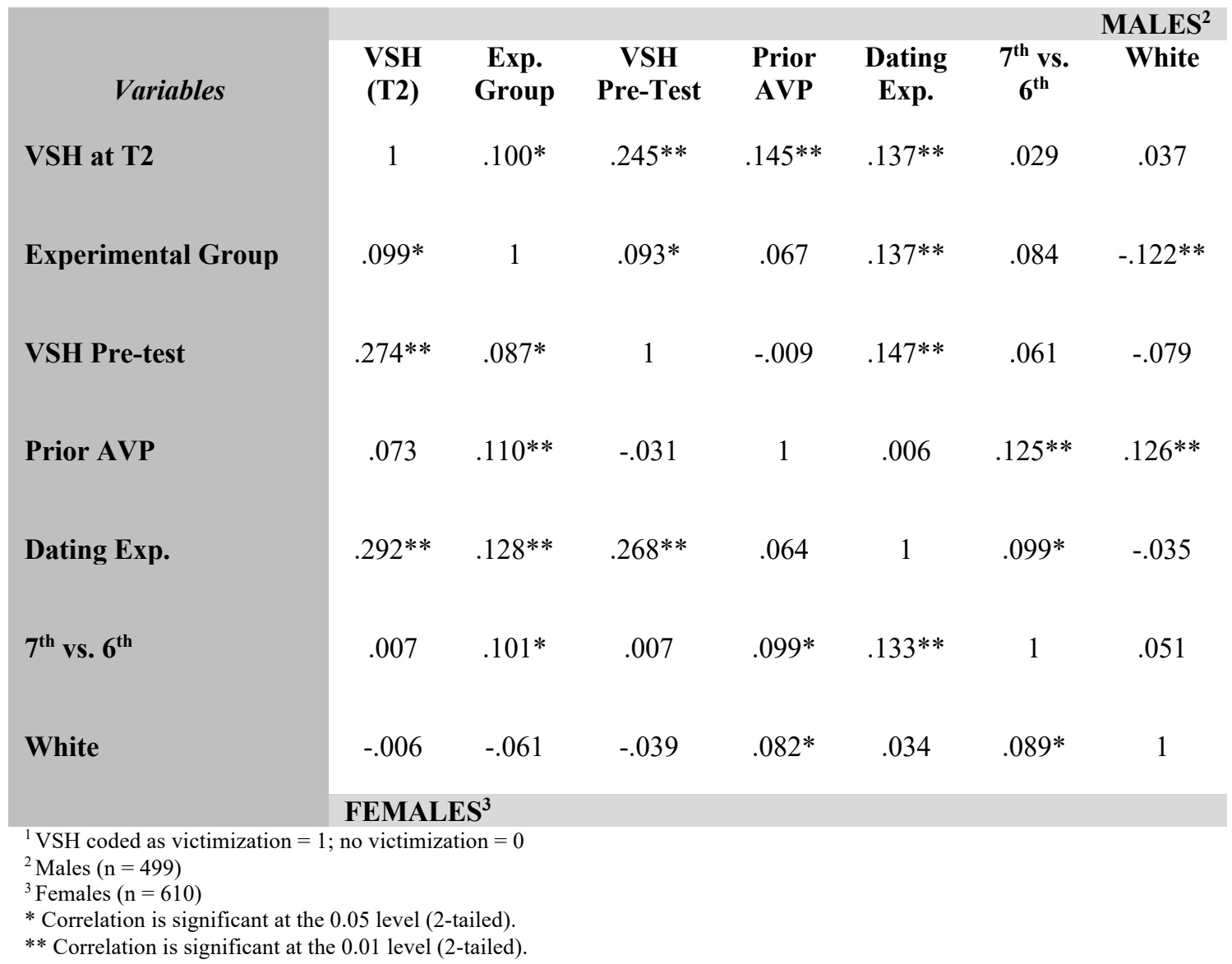




\section{Multinomial Logistic Regression Models}

The results of the multinomial logistic regressions are reported in Tables 6 and 7. The regression models attempt to identify the individual-level factors that differentiate victims from non-victims when the gender of the perpetrator is considered (see Models 1 - 3 in Table 6). The statistical procedure used also allows for comparisons among victims, and these results are included in Table 7 (see Models $4-6$ ). The model fits the data reasonably well, with a Model Chi-square of $257.299(p<.001)$, a Cox \& Snell $R^{2}=$ .207 , and a Nagelkerke $R^{2}=.225$.

Cross-gender victimization versus non-victimization. Model 1 suggests that when students who experienced cross-gender victimization were compared to nonvictims, the victims of verbal sexual harassment were more likely to be students who acknowledged VSH victimization at the baseline interview (pre-test), those with dating experience, students who were part of the experimental group (received the program), and female students. Specifically, the results indicated that compared to the control group, the odds for students in the experimental group reporting VSH victimization by the opposite sex relative to non-victimization increased by a factor of $1.481(p<.10)$. For each unit increase in pre-test victimization, the odds of post-test victimization increased by $29.3 \%(\mathrm{~B}=.257 ; \exp (B)=1.293 ; p<.001)$. When controlling for the other variables in the model, the odds of being victimized by a student of the opposite sex relative to non-victimization were $154 \%$ higher $(\mathrm{B}=.930 ; \exp (B)=2.536 ; p<.001)$ for students with dating experience compared to students with no dating experience. Finally, the odds of being a victim of the opposite sex versus not being a victim was more than twice as high for female students when compared to male students $(\mathrm{B}=.885 ; \exp (B)=2.422 ; p<$ 
.001 ), given the other variables in the model are held constant. Prior exposure to an antiviolence educational program $(p=.824)$, respondent's age $(p=.182)$ and respondent's race/ethnicity $(p=.553)$ did not differentiate victims of cross-gender victimization from non-victims.

Same-gender victimization versus non-victimization. When same-gender victims are compared to non-victims (Model 2), results show that students who reported VSH victimization at the pre-test were significantly more likely to report victimization at the post-test. For each unit increase in pre-test victimization, the odds of post-test victimization increased by $19.7 \%(\mathrm{~B}=.180 ; \exp (B)=1.197 ; p<.01)$. Second, the odds of being victimized by a perpetrator of the same sex were $71.3 \%$ higher for students who noted prior participation in an anti-violence program when compared to students who had not been exposed to an educational program before the current experiment started $(\mathrm{B}=$ $.538 ; \exp (B)=1.713 ; p<.05)$. Third, when compared to males, females were significantly less likely to report at post-test that they had been victimized by other females. Specifically, relative to non-victims, the odds for a female student to be victimized by another female student were $76 \%$ lower than the odds of a male student being victimized by another male student $(\mathrm{B}=-1.428 ; \exp (B)=.240 ; p<.001)$, given the other variables in the model are held constant. Lastly, exposure to experimental treatment $(p=.365)$, dating experience $(\mathrm{p}=.384)$, respondent's age $(p=.180)$, and respondent's race $(p=.274)$ did not significantly differentiate same-gender victims from non-victims.

Victimization by both genders versus non-victimization. Model 3 shows the results of the multinomial logistic regression when students victimized by both male and female peers were compared to students who did not report verbal sexual harassment 
victimization at the post-test. The significant predictors of VSH victimization by both male and female peers compared to non-victims included pre-test total VSH victimization, dating experience, and prior participation in an anti-violence program. The non-significant predictors were treatment effects $(p=.311)$, gender $(p=.394)$, race $(p=$ $.395)$, and age $(p=.167)$.

The odds of students experiencing VSH victimization by both genders compared to non-victims were influenced by three variables measured in this model. First, relative to non-victims, students who reported VSH victimization at the pre-test were significantly more likely to report at post-test they had been victimized by both male and female peers. For each unit increase in pre-test victimization, the odds of post-test victimization increased by $46 \%(\mathrm{~B}=.378 ; \exp (B)=1.459 ; p<.001)$. Second, relative to non-victims, the odds of being victimized by both male and female peers were $137 \%$ higher for those with dating experience compared to students who reported no dating experience $(\mathrm{B}=.864 ; \exp (B)=2.373 ; p<.001)$. Third, victimization by both male and female peers was $106 \%$ more likely to be reported by students who participated in a prior anti-violence program $(\mathrm{B}=.722 ; \exp (B)=2.058 ; p<.001)$, given the other variables in the model are held constant.

There was no significant difference in the odds of students exposed to treatment (experimental group) being sexually harassed verbally from both male and female peers compared to non-victims $(p=.311)$. The student's gender did not predict the odds of being VSH by both male and female peers compared to non-victims ( $p=.394)$. A student's age (i.e., grade) did not predict the odds of being VSH by both genders 
compared to non-victims $(p=.167)$. And finally, a student's race did not predict the odds of being sexually harassed verbally by both genders compared to non-victims $(p=.395)$. 


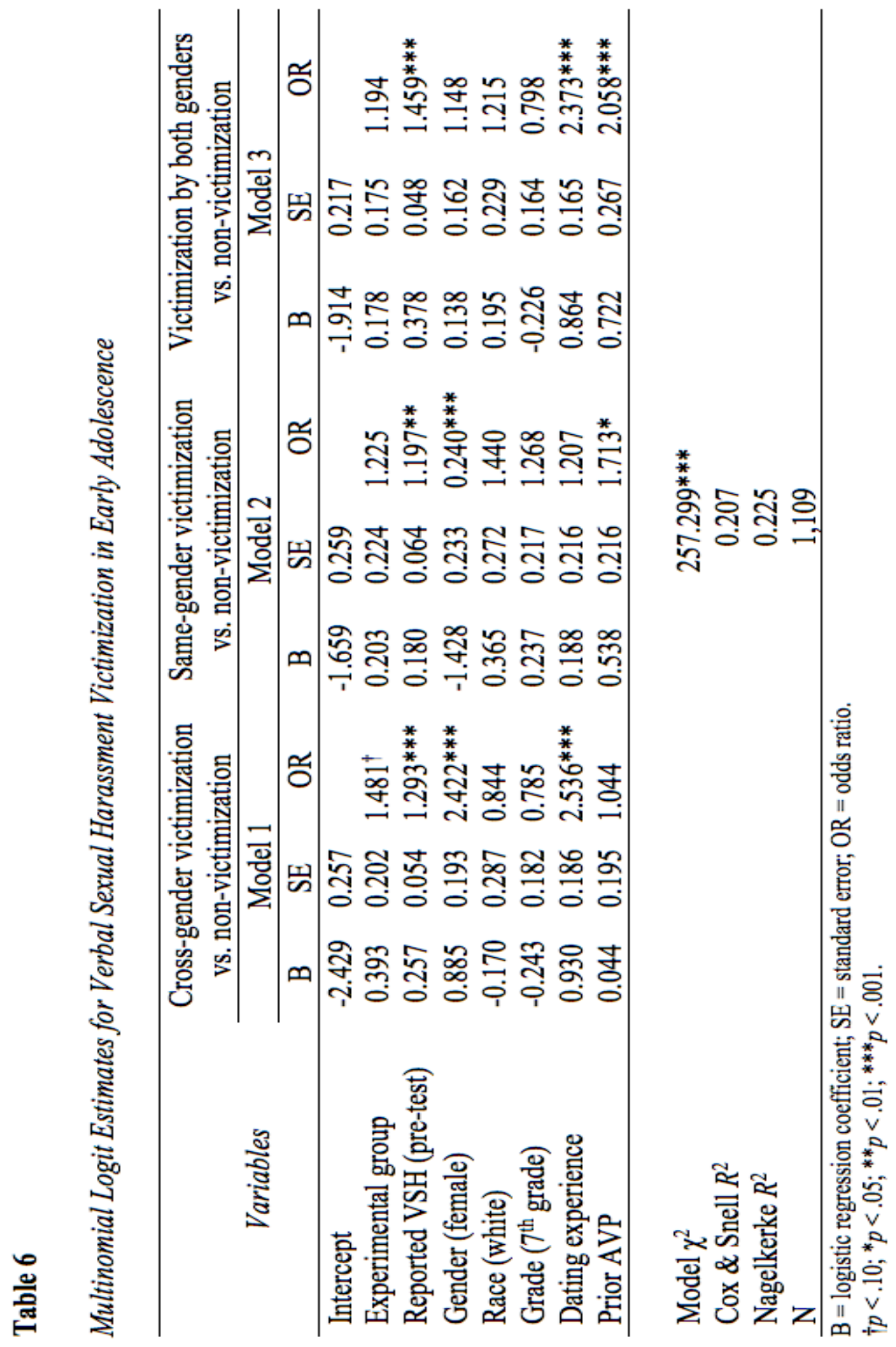


Table 7 includes the estimated effects of the selected predictors on verbal sexual harassment victimization, when inter-group comparisons among victims are made. While model 4 intends to determine what factors differentiate cross-gender victims from samegender victims, models 5 and 6 use as a reference group the subsample of students who have been victimized by both male and female students.

Cross-gender victimization versus same-sex victimization. The results of the multinomial logistic regression for students victimized by peers of the opposite sex compared to students victimized by verbal sexual harassment by same-sex peers at the post-test (Model 4) indicate that dating experience, gender, prior participation in an antiviolence program, and age significantly differentiate cross-gender victims from samegender victims. No significant treatment effect was identified $(p=.486)$. Additionally, pre-test VSH victimization $(p=.270)$ and race $(p=.395)$ did not have significant effects. Relative to students who experienced only same-sex victimization, students who reported cross-gender victimization are more likely to be females, students who do not have dating experience, students previously exposed to an anti-violence program, and younger students. Specifically, the odds for a female student to be victimized by a male student are ten times higher than the odds of a male student to be victimized by a female student $(\mathrm{B}=2.313 ; \exp (B)=10.102 ; p<.001)$, relative to same-sex victimization. Compared to students without dating experience, those who acknowledged dating are significantly less likely to report cross-gender victimization $(\mathrm{B}=-0.495 ; \exp (B)=.610 ; p<.05)$ rather than same-sex victimization. Students enrolled in the $7^{\text {th }}$ grade are also less likely to report cross-gender victimization vs. same-gender victimization than their younger counterparts $(\mathrm{B}=-0.480 ; \exp (\mathrm{B})=.619 ; p<.10)$. Conversely, the odds of being a cross-gender victim 
vs. a same-gender victim are twice higher for students who have been exposed to an antiviolence educational program $(\mathrm{B}=.743 ; \exp (B)=2.101 ; p<.01)$.

\section{Cross-gender victimization versus victimization by both genders. Model 5}

presents the results of the multinomial logistic regression when students who reported only cross-gender VSH victimization are compared to those victimized by both male and female peers. Results show that, relative to those who reported being sexually harassed by both male and female peers, students victimized only by peers of the opposite sex are more likely to be females. Conversely, students who reported VSH victimization at the baseline interview and those with dating experience were significantly less likely to report cross-gender victimization rather than victimization by both male and female peers. The odds of being victimized only by a peer of the opposite sex vs. being a victim of both male and female peers decreased by approximately $11.4 \%$ with each unit increase in VSH victimization reported at the pre-test $(\mathrm{B}=-0.121 ; \exp (B)=.886 ; p<.10)$. Those with dating experience were also significantly less likely to report victimization by the opposite sex vs. victimization by both genders, when compared to their peers without dating experience $(\mathrm{B}=-0.678 ; \exp (B)=.507 ; p<.001)$. Compared to male students victimized by females, the odds of female students to report VSH victimization only by male peers vs. victimization by both male and female peers are twice higher $(\mathrm{B}=.746$; $\exp (B)=2.109 ; p<.001$, given the other variables in the model are held constant.

There was no significant difference in the odds in the post-test for VSH victimization by peers of the opposite sex compared to the same type of victimization by both male and female peers in the experimental treatment group when compared to the 
control group $(p=.334)$. Race $(p=.228)$ and age $(p=.933)$ did not differentiate students who experienced cross-gender victimization only from those who reported being sexually harassed by both male and female peers.

Same-sex victimization versus victimization by both genders. Model 6 shows four significant predictors for students being victimized by peers of the same sex compared to students victimized by both male and female peers. The significant predictors are VSH victimization at pre-test, prior participation in an anti-violence program, gender, and age. The non-significant predictors are treatment $(p=.918)$, dating experience $(p=.424)$, and race $(p=.565)$.

The results show that with each unit increase in VSH victimization reported when the baseline interview (pre-test) was conducted, the odds of being victimized at post-test by a peer of the same sex versus being victimized by both male and female peers decrease by $18 \%(\mathrm{~B}=-0.198 ; \exp (B)=.820 ; p<.01)$. Students who were not exposed to an anti-violence program prior to the implementation of the Shifting Boundaries program compared to students who did participate in an educational program were significantly less likely to acknowledge only same-sex victimization versus victimization by both male and female peers $(\mathrm{B}=-0.676 ; \exp (B)=.509 ; p<.01)$. Compared to male students being victimized by other males, the odds for females to be victimized by other females versus being victimized by peers in both gender groups were almost $80 \%$ lower than male students $(\mathrm{B}=-1.566 ; \exp (B)=.209 ; p<.001)$. Conversely, for $7^{\text {th }}$ graders, the odds of being victimized only by peers of the same-sex versus being victimized by both boys and girls are $59 \%$ higher than they are for $6^{\text {th }}$ graders $(B=.463 ; \exp (B)=1.589 ; p<.10)$, given the other variables in the model are held constant. 


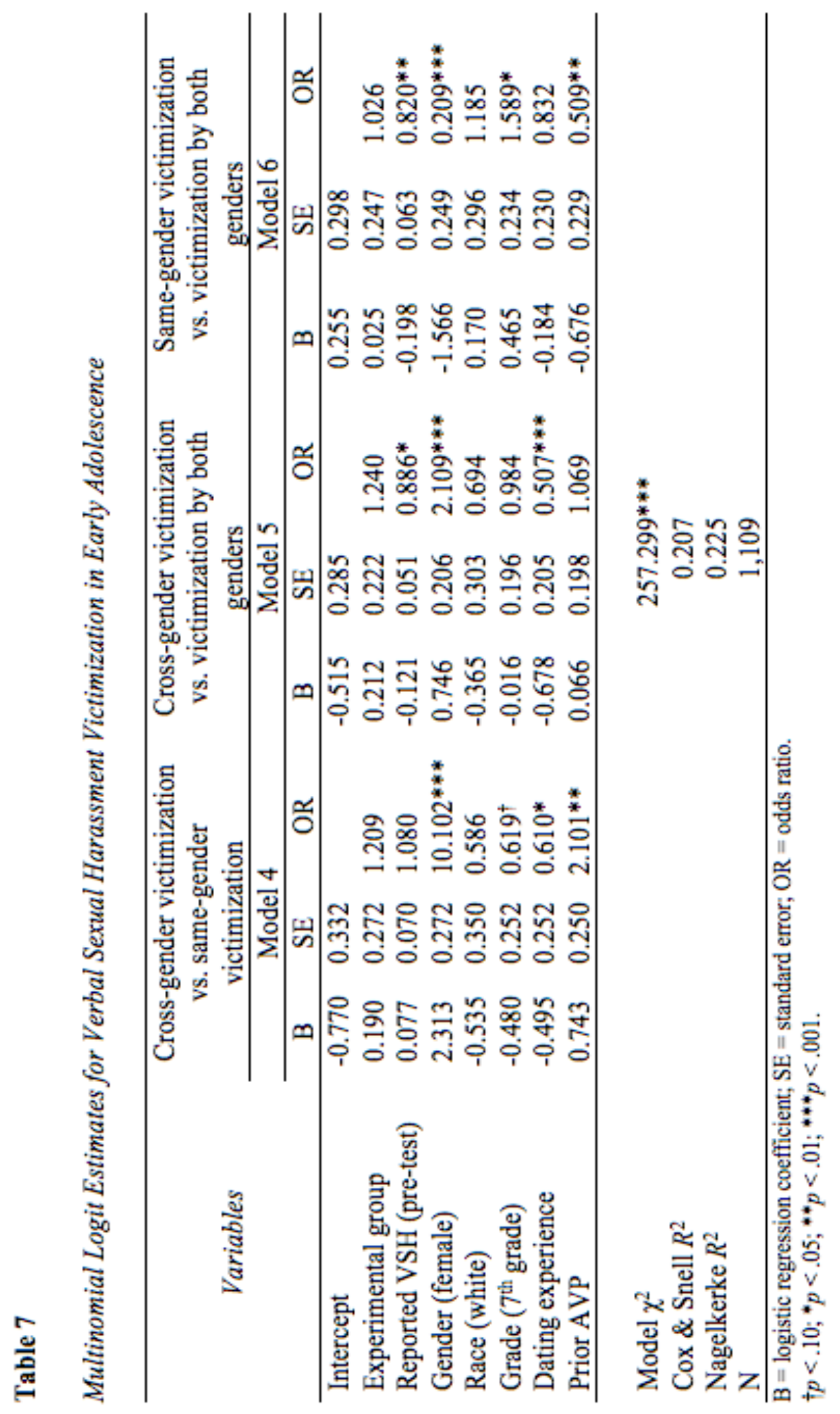


To summarize, in five out of six inter-group comparisons students in the experimental group did not differ from students in the control group, in terms of reported verbal sexual harassment victimization. Treatment participants were, however, significantly more likely to report cross-gender victimization than those in the comparison group.

Students who reported pre-test victimization were more likely to report revictimization. Among victims, those who reported pre-test victimization were more likely to report being victimized by both boys and girls, when interviewed at post-test. In general, students who reported prior exposure to an anti-violence educational program were more likely to report verbal sexual harassment victimization at post-test.

As hypothesized, students with dating experience were significantly more likely to report cross-gender victimization, as well as victimization by both boys and girls. While age and race did not differentiate victims from non-victims and did not influence inter-group differences among victims, gender did. Girls were significantly more likely to report cross-gender victimization, while boys were significantly more likely to report same-gender victimization.

\section{Assessing the Program's Effectiveness}

The multivariate analyses previously presented examined reported verbal sexual harassment when controlling for a set of predictors (i.e., independent variables). One of the independent variables was participation in the Shifting Boundaries program. Although the experimental design corresponding to the Shifting Boundaries program randomly assigned respondents to experimental and comparison groups to assure internal validity, due to the exclusion of multiple cases with missing information for the purposes of this 
research, selection bias became a potential threat to internal validity. Preliminary analyses showed that, with the exception of gender, the control and the experimental groups differed significantly in terms of several predictors, which, based on a review of the literature are considered to be associated with verbal sexual harassment victimization. Specifically, compared to the control group, the experimental group included a larger proportion of students with dating experience, had more students enrolled in the $7^{\text {th }}$ grade, had more minority students, and had a larger percent of students who reported pretreatment exposure to an anti-violence educational program. In order to compensate for the potential selection bias and significant differences between the experimental and control groups within the current research sample, propensity score matching was used to create equivalent experimental and control groups.

The fundamental feature of the propensity score matching model (PSM) (Rosenbaum, 2002; Rosenbaum \& Rubin, 1983, 1985) is that it balances data through resampling or matching nontreated participants to treated ones on probabilities of receiving treatment (i.e., the propensity score) and permits follow-up bivariate or multivariate analyses as would be performed on a sample generated by a randomized experiment. Reducing the dimensionality of covariates to a one-dimensional score (the propensity score) is a substantial contribution that leverages matching (Guo \& Fraser, 2015). A propensity score is the conditional probability that a subject will be in the treatment group, given his/her characteristics. It can take values from zero to 1 . These scores (probabilities) are estimated based on characteristics of the groups being compared. They allow controlling for much, if not all, of the pre-test differences (Rubin, 1974). They improve the internal validity of between-group comparisons so that an 
estimate of the effect of the variable represented by the groups will be as close as possible to the true effect of the variable. In optimal circumstances, propensity scores allow an unbiased estimate of this effect (Holmes, 2014, p.12).

After obtaining propensity scores for 1,109 cases included in the propensity score model, the study applied a matching procedure that used a without-replacement sampling method and a match tolerance equal to .001. Matching without replacement requires each untreated unit to be uniquely matched to a treated unit. This sampling method was preferred to sampling with replacements because it allowed more untreated cases to be used in the matching procedure, reducing in this way the variance of the estimate (Reynolds \& DesJardins, 2009, p. 70). Additionally, as results included in Table 8 suggest, the sampling procedure did not increase the bias of the estimates. By setting the match tolerance (or fuzz factor) at .001 , the precision of the matching procedure was greatly increased. Tolerance is expressed as a proportion of the propensity score, so a tolerance of .001 allows for a difference of .001 in the overall propensity score. By using a match tolerance close to zero, the matches selected were as close as possible to exact matches. Case control statistics indicated there were 336 exact matches and only 3 fuzzy matches (i.e., less than perfect matches).

Since the control group had a smaller number of respondents with complete information $(\mathrm{N}=351)$ than the experimental group $(\mathrm{N}=758)$, the sample obtained after cases were matched based on similar propensity scores was smaller than the initial sample. However, only 12 cases from the control group could not be matched with cases from the experimental group. In sum, the final sample included 678 cases (339 cases in the experimental group; 339 cases in the control group). 
Table 8 includes descriptive statistics and model adequacy checks that show the degree to which PSM was effective in reducing observable selection bias. The bias measure (i.e., standardized mean difference in percent) represents the amount of bias corresponding to the selected covariates when the experimental and the control groups are compared. According to Rosenbaum and Rubin (1985), bias values higher than 20 indicate unbalance. It can be noted that before matching there was one covariate (dating experience) that had a value higher than $20(\mathrm{SMD}=28)$ and three other covariates had values close to 20 . Statistical tests that examined differences in means indicated that before PSM, the control and the experimental groups were comparable in terms of gender distribution only. Levene's tests of equality of variances also showed that the variations around the mean for all predictors, except gender, were unequal when the experimental and the control groups were compared. Post-matching results indicated that balance between the experimental and the control group was achieved for all predictors. Specifically, when the control and the experimental groups were compared, all standardized mean differences (SMDs) were close to zero and all variance ratios (VRs) were close to 1 (see Thoemmes, 2012). 
Table 8

Covariate Balance for Program Selection Before and After Matching

\begin{tabular}{|c|c|c|c|c|c|c|c|c|}
\hline \multirow[b]{2}{*}{ Variables } & \multirow[t]{2}{*}{ Sample } & \multicolumn{2}{|c|}{ Experimental group } & \multicolumn{2}{|c|}{ Control group } & \multirow{2}{*}{$\begin{array}{c}\text { Bias } \\
\text { (SMD) }\end{array}$} & \multirow[t]{2}{*}{$\mathrm{F}$} & \multirow[t]{2}{*}{$t$} \\
\hline & & $\mathrm{M}$ & $\mathrm{SD}$ & $\mathrm{M}$ & $\mathrm{SD}$ & & & \\
\hline \multirow[t]{2}{*}{ Dating Exp. } & Total & .453 & .498 & .316 & .466 & 27.9 & $89.69 * * *$ & $4.475^{* * *}$ \\
\hline & Matched & .307 & .461 & .304 & .460 & 0.64 & .028 & .083 \\
\hline \multirow[t]{2}{*}{ Gender (female) } & Total & .558 & .497 & .533 & .499 & 5.1 & 1.935 & .787 \\
\hline & Matched & .539 & .499 & .539 & .499 & 0.00 & .00 & .000 \\
\hline \multirow[t]{2}{*}{ Age $\left(7^{\text {th }}\right.$ grade $)$} & Total & .610 & .488 & .513 & .501 & 19.8 & $17.51 * * *$ & $3.057 * * *$ \\
\hline & Matched & .519 & .500 & .522 & .499 & 0.59 & .023 & -.077 \\
\hline \multirow[t]{2}{*}{ Race (white) } & Total & .117 & .322 & .185 & .389 & -19.6 & $35.43 * * *$ & $-2.844 * * *$ \\
\hline & Matched & .159 & .366 & .156 & .364 & 0.80 & .044 & .105 \\
\hline \multirow[t]{2}{*}{ Pre-AVP } & Total & .373 & .484 & .279 & .449 & 19.8 & $45.19 * * *$ & $3.166^{* * *}$ \\
\hline & Matched & .292 & .455 & .289 & .454 & 0.64 & .029 & .084 \\
\hline
\end{tabular}

Note: Bias $=$ standardized mean difference (SMD) in percent

$\mathrm{F}=$ Levene's test for homogeneity of variances; $t=$ independent-samples t-test.

$* p<.05 ; * * p<.01: * * * p .001$

In Table 9, the first multinomial logistic regression examines the program effect when controlling for victimization reported at baseline (pre-test). Results indicate that when controlling for prior reported victimization, respondents in the experimental group did not differ from those in the control group in terms of same-sex victimization or victimization by both girls and boys. However, students in the treatment group were more likely to report cross-gender victimization $(\mathrm{B}=.407 ; \exp (B)=1.481 ; p<.10)$. Pretreatment victimization is significantly and positively associated with all types of posttreatment victimization at $p<.001$. 
Table 9

Multinomial Logit Estimates for VSH Victimization in Early Adolescence ${ }^{1}$

\begin{tabular}{|c|c|c|c|c|c|c|c|c|c|}
\hline \multirow[b]{3}{*}{ Variables } & \multicolumn{3}{|c|}{$\begin{array}{l}\text { Cross-gender victimization } \\
\text { vs. non-victimization }\end{array}$} & \multicolumn{3}{|c|}{$\begin{array}{c}\text { Same-gender victimization } \\
\text { vs. non-victimization }\end{array}$} & \multicolumn{3}{|c|}{$\begin{array}{l}\text { Victimization by } \\
\text { both genders } \\
\text { vs. non-victimization }\end{array}$} \\
\hline & \multicolumn{3}{|c|}{ Model 1} & \multicolumn{3}{|c|}{ Model 2} & \multicolumn{3}{|c|}{ Model 3} \\
\hline & $\mathrm{B}$ & $\mathrm{SE}$ & OR & $\mathrm{B}$ & SE & OR & $\mathrm{B}$ & SE & OR \\
\hline Intercept & -1.745 & 0.188 & & -1.875 & 0.204 & & -1.429 & 0.165 & \\
\hline $\begin{array}{l}\text { Treatment } \\
\text { (Exp. Group) }\end{array}$ & 0.407 & 0.225 & $1.481^{\dagger}$ & 0.347 & 0.249 & 1.415 & -0.023 & 0.208 & 0.978 \\
\hline \multirow[t]{2}{*}{$\begin{array}{l}\text { Pre-test VSH } \\
\text { victimization }\end{array}$} & 0.274 & 0.060 & $1.315^{* * *}$ & 0.188 & 0.070 & $1.207^{* *}$ & 0.346 & 0.055 & $1.413 * * *$ \\
\hline & & & $\begin{array}{r}\text { Mo } \\
\text { Nagelke }\end{array}$ & $\begin{array}{l}\text { lel } \chi^{2} \\
\text { ke } R^{2}\end{array}$ & $\begin{array}{c}53.462 * \\
0.083\end{array}$ & & & & \\
\hline
\end{tabular}

In Table 10, the subsequent multinomial logistic regression identifies a significant treatment effect only in one instance. The effects of the other predictors are consistent with the results previously reported (see Table 6, Models 1-3). When controlling for all the predictors included in the analysis, respondents in the experimental group reported being sexually harassed verbally by a student of the opposite sex significantly more often $(\mathrm{B}=.424 ; \exp (B)=1.528 ; p<.10)$ than those in the control group. No significant differences between the experimental and the control group were identified when those verbally harassed by a student of the same sex or by both, girls and boys were compared with non-victims. 
Table 10

Multinomial Logit Estimates for VSH Victimization in Early Adolescence ${ }^{l}$

\begin{tabular}{|c|c|c|c|c|c|c|c|c|c|}
\hline \multirow[t]{3}{*}{ Variables } & \multirow{2}{*}{\multicolumn{3}{|c|}{$\begin{array}{c}\begin{array}{c}\text { Cross-gender } \\
\text { victimization } \\
\text { vs. non-victimization }\end{array} \\
\text { Model } 1\end{array}$}} & \multicolumn{3}{|c|}{$\begin{array}{l}\text { Same-gender victimization } \\
\text { vs. non-victimization }\end{array}$} & \multicolumn{3}{|c|}{$\begin{array}{c}\text { Victimization by } \\
\text { both genders } \\
\text { vs. non-victimization }\end{array}$} \\
\hline & & & & \multicolumn{3}{|c|}{ Model 2} & \multicolumn{3}{|c|}{ Model 3} \\
\hline & B & SE & OR & B & SE & OR & B & SE & OR \\
\hline Intercept & -2.648 & 0.315 & & -1.634 & 0.290 & & -1.565 & 0.247 & \\
\hline $\begin{array}{l}\text { Treatment } \\
\text { (Exp. Group) }\end{array}$ & 0.424 & 0.230 & $1.528^{\dagger}$ & 0.346 & 0.255 & 1.414 & -0.019 & 0.210 & 0.981 \\
\hline $\begin{array}{l}\text { Pre-test VSH } \\
\text { victimization }\end{array}$ & 0.256 & 0.063 & $1.292 * * *$ & 0.165 & 0.073 & $1.179 * *$ & 0.331 & 0.057 & $1.393 * * *$ \\
\hline Prior AVP & 0.175 & 0.269 & 1.191 & 0.261 & 0.279 & 1.298 & 0.418 & 0.232 & $1.519^{\dagger}$ \\
\hline Dating Exp. & 0.830 & 0.254 & $2.294 * * *$ & 0.029 & 0.289 & 1.029 & 0.609 & 0.232 & $1.838^{* *}$ \\
\hline $\begin{array}{l}\text { Gender } \\
\text { (female) }\end{array}$ & 1.107 & 0.258 & $3.025^{* * *}$ & -1.328 & 0.286 & $0.265 * * *$ & 0.023 & 0.212 & 1.024 \\
\hline $\begin{array}{l}\text { Age } \\
\left(7^{\text {th }} \text { grade }\right)\end{array}$ & -0.192 & 0.242 & 0.826 & 0.335 & 0.269 & 1.397 & -0.376 & 0.220 & $0.686^{\dagger}$ \\
\hline Race (white) & -0.216 & 0.245 & 0.806 & 0.187 & 0.328 & 1.206 & 0.093 & 0.291 & 1.097 \\
\hline & & & $\begin{array}{r}\text { Mc } \\
\text { Nagelke }\end{array}$ & $\begin{array}{l}\text { del } \chi^{2} \\
\text { ke } R^{2}\end{array}$ & $\begin{array}{r}133.63 \\
0.196 \\
\end{array}$ & & & & \\
\hline
\end{tabular}

In sum, when observable selection bias was minimized through propensity score matching to create a comparison group of non-participants who were not significantly different from the program participants, no significant differences in any type of VSH victimization were found between the comparison group and those who participated in treatment, in the direction anticipated by the Shifting Boundaries program. In fact, in one instance, consistent with previous results (see Table 6), a backfire effect could be noticed. "A backfire effect reflects an outcome that is the opposite of that expected or desired" when impact evaluations are conducted (Weisburd et al., 2003, p. 42). The findings show that students exposed to the treatment reported post-test cross-gender victimization 
significantly more often than the comparison group. The overall findings, limitations and future research, and policy implications will be discussed in the next chapter. 


\section{CHAPTER V}

\section{DISCUSSION}

Currently, the general consensus in our society is that sexual harassment is unacceptable behavior regardless of who is the perpetrator and who is the victim. Since 1972, Title IX (i.e., guidelines established by the U.S. Department of Education) has sought to protect students of any age and gender from sexual harassment and sexual violence victimization. Many researchers have examined sexual harassment and its effects on the student population. What they have found is that sexual harassment starts early and escalates during middle school and high school, and for some students, it continues to follow them into adulthood (AAUW, 2011; Espelage \& Holt, 2007; Halpern et al., 2009; Hand \& Sanchez, 2000; McMaster et al., 2002; Pellegrini, 2001). And, while the collateral consequences of sexual harassment are still being explored, we do know that it results in a wide range of negative developmental problems, including diminished mental and physical health, school performance, social isolation, and suicidality (Ackard \& Neumark-Sztainer, 2002; Corbett et al., 1993; Dahlquvist et al., 2016; Offendhauer \& Buchalter, 2011). While students might experience any number of these negative consequences because they have been victims of sexual harassment, they are also more likely to experience revictimization (Banyard \& Cross, 2008; Exner-Cortens et al., 2013; Finkelhor et al., 2007).

Although past research has examined sexual harassment and its deleterious consequences among students, very few studies have examined the predictors of sexual 
harassment among younger students (i.e., prior to the $8^{\text {th }}$ grade). Even fewer studies have delineated between verbal and physical sexual harassment. Therefore, the current research aimed to fill a gap in the sexual harassment literature by identifying patterns of verbal sexual harassment among $6^{\text {th }}$ and $7^{\text {th }}$ grade students, including an assessment of the effects of prior verbal sexual harassment victimization, prior exposure to anti-violence educational programming, dating experience, gender, age, and race had on the likelihood of verbal sexual harassment victimization. Hypotheses were constructed within the context of Gender Order Theory (i.e., hegemonic masculinity) and Social Script Theory (i.e., sex scripts). The study also examined the outcomes of an intervention program meant to reduce verbal sexual harassment among a middle school population in New York City.

The first noteworthy finding from the current study is the likelihood of verbal sexual harassment victimization among $6^{\text {th }}$ and $7^{\text {th }}$ graders by gender. As hypothesized, girls experienced more cross-gendered victimization compared to boys at post-test. In fact, the findings suggest that girls were more than twice as likely to be verbally sexually harassed by boys compared to boys being victimized by girls. The present findings were not consistent with prior research (see Rolfe \& Schroeder, 2017) regarding boys experiencing more verbal sexual harassment than girls.

The study also found that boys were four times more likely to be victimized by other boys compared to same-gender victimization among girls. Such findings are not a surprise based on current dominant social norms that define gender roles that embody power dynamics and teach boys/men to seek authority and dominance not only over girls/women, but also over boys/men who are perceived as effeminate (Connell \& 
Messerschmidt, 2005). It is evident from the current findings that from a very early age, boys are embracing the hegemonic masculinity concept by using verbal sexual harassment as a tool to establish dominance and gender inequality among their peers. While scholars and educators have taken notice of this issue by developing anti-violence and sexual harassment programs aimed to teach children appropriate sexual boundaries, the reality is that our society functions as a patriarchal society in which hegemonic masculinity behaviors are embraced and rewarded regardless of race and socioeconomic status. Until there is a shift in these behaviors, girls/women and perceived weaker boys/men will unfortunately continue to be victimized by boys/men seeking and maintaining dominance over them (Espelage et al., 2012; Fineran et al., 2009; Gruber \& Fineran, 2009; Foshee et al., 2004; Taylor et al., 2012).

The second noteworthy finding from the current study was the likelihood of VSH revictimization. Students who reported being VSH by their peers at pre-test were also more likely to report VSH victimization at the post-test. One possible explanation could be the influence of our patriarchal society that facilitates and further embraces gender inequality. As a result of this widely held ideology, it consequently has led to a cyclical effect of victimization for females, males who may be perceived as being effeminate, or males of minority status. Prior studies have suggested that being victimized at an early age leads to revictimization throughout the life course. The same has also been found among those who predominately engage as the perpetrator of these types of behaviors (Chiode et al., 2009; McMaster et al., 2002; Peterson \& Hyde, 2009; Wolfe et al., 1998). Reflective of prior research, the current study also found that students who reported victimization were significantly more likely to report revictimization across all 
three models (cross-gender, same-sex, and by both genders) of victimization versus nonvictimization (Banyard \& Cross, 2008; Exner-Cortens et al., 2013; Finkelhor et al., 2007). Although it is clear that prior victimization leads to revictimization, we cannot discount that revictimization is most likely attributed to boys at this age beginning to test the nature of socially structured gender roles and sexual relationships with females.

The third noteworthy finding from the current study is the likelihood of victimization being influenced by age. Prior scholarship has shown that sexual harassment revictimization is likely to continue throughout one's life course, especially as they age into adulthood. (McMaster et al., 2002; Peterson \& Hyde, 2009; Polce-Lynch et al., 2001). Despite past studies establishing patterns of victimization by age, the current study did not find support for the hypothesis that $7^{\text {th }}$ grade students would report more verbal sexual harassment than $6^{\text {th }}$ grade students. In fact, age did not differentiate victims of verbal sexual harassment from non-victims. This finding, however, may have been the result of the nature of the sample, that is the limited variation in the students' ages. The study included only students in the $6^{\text {th }}$ and $7^{\text {th }}$ grades and it is quite possible that many respondents, especially female students, had yet to experience a biological and psychological pivotal change that would encourage them to want to explore the dating culture and/or sexual encounters.

Another possibility could be due to the limited number of grades in this study, which did not allow for variance in age to be explored. Because this study only included $6^{\text {th }}$ and $7^{\text {th }}$ graders, the similarities in age between the two grades lacked variance because students in the sixth grade could be older than seventh graders and vice-versa. Therefore, finding differences between grade-levels was limited. Future research may want to 
expand the age group by including more grade levels in order to find similarities and differences in VSH victimization and perpetration among pre-adolescent and adolescent students.

The fourth finding in this study is dating experience, which was found to increase the odds of being a victim of verbal sexual harassment, as originally hypothesized. Despite the student's age not being a predictor of verbal sexual harassment, it was not a surprise that students with dating experience were more likely to be victimized. Other studies reported similar results as well (Rolfe \& Schroeder, 2017; Taylor et al., 2012). It appears that students with dating experience foster or perpetuate cross-gendered victimization and victimization by both genders, and that same-sex victimization is most likely to occur among students who have no dating experience. As previously noted, sex scripts are cultural norms in which we navigate and negotiate sexual interactions with one another (Gagnon \& Simon, 1973). And, while different for men and women, it is the foundation to the negotiating process for establishing boundaries and consent throughout our social and sexual interactions. Therefore, the results from the current study suggest that early adolescent romantic relationships facilitate both genders to engage in their shared cultural understanding of sex scripts through the use of verbal sexual harassment. It is also quite possible that students who engage in the dating cultural are perceived as being promiscuous; thus, leading to VSH victimization from their peers and former partners (Espelage \& Holt, 2007; Rolfe \& Schroeder, 2017). Verbal sexual harassment has also been viewed as "just teasing or flirting" and therefore has resulted in being normalized by students and teachers as part of everyday culture (deLara 2008; Hlavka, 2014; Litchy \& Campbell, 2012). Despite students seeing VSH as nothing more than 
another form of teasing or fliting, VSH can be used in the context of soliciting sexual attention. Adolescents, however, are typically not well informed or equipped to decipher between teasing/flirting and the intent behind verbal sexual harassment from their peers. For those who cannot discern such behaviors by establishing and enforcing proper boundaries run the risk of being subjected to further verbal sexual victimization, as well as physical sexual violence (Muehlenhard, 2011).

The fifth outcome of the current study found further support of prior research in that racial and ethnic minorities are significantly more affected by sexual harassment victimization than Caucasian students (Alleyene-Green et al., 2012; Goldstein et al., 2007). The hypothesis that non-white students would be victims of verbal sexual harassment more often than Caucasian students was not supported. Given the use of hegemonic masculinity as a perspective to define gender roles, a difference based on race/ethnicity would not be expected as masculinity success as a goal is a feature of all race/ethnic subcultures (Connell \& Messerschmidt, 2005). The only differences come from the manner in which it is accomplished as a function of the availability of social resources (Archer, 2004). Additionally, this failure to find race/ethnicity related to sexual harassment victimization is not unsupported by prior research (Espelage \& Holt, 2007). Lastly, this finding may be a product of the sample used in the present research. The current sample included significantly fewer Caucasian students (14\%) than race/ethnic minority students (86\%). This skewed distribution may have influenced the results. Further research is needed to determine the nature and extent of race/ethnicity as a factor in sexual harassment victimization. 
Another hypothesis in this research predicted that students who reported prior participation in an anti-violence program before the pre-test would report at post-test lower levels of verbal sexual harassment victimization than students who did not report participation in an anti-violence educational program before exposure to the current program. The findings did not support the anticipated effect of the hypothesis. In fact, the findings suggest that those who attended a program were more likely to report same-sex and both-gender victimization; the program exposure did not differentiate cross-gender victims from non-victims. In short, prior exposure to an educational program did not have the anticipated effect. A possible explanation could be due to students not believing that teasing and flirting constitutes as verbal sexual harassment or that it causes harm. While the current study did not find support for educational programs to reduce VSH victimization, prior scholarship has found an overall reduction in sexual violent behaviors (Espelage et al., 2013; Foshee et al., 2004; Taylor et al., 2010), but program effectiveness diminished over time (Fellmeth et al., 2013; Ting, 2009). Nonetheless, it appears that prior anti-violence programming resulted in higher reported rates of victimization within the current sample. Clearly more research is needed on the efficacy of anti-violence, antisexual harassment programming and their ability to produce both short and long-term effects in curtailing these types of behaviors.

The final result of this study is related to an assessment of the current Shifting Boundaries program, and the extent to which it resulted in a short-term effect among students exposed to the program. Exposure to the program did not appear to result in decreased reporting of verbal sexual harassment victimization when the experimental (exposure to the program) and control group results were compared. The hypothesis that 
students exposed to the violence prevention program would report a significantly lower level of verbal sexual harassment victimization than the comparison group was not supported by evidence. Although preliminary analyses showed a reduction in VSH victimization in the experimental group from the pre-test to the post-test for the entire sample and in both subsamples differentiated by respondent's gender, students in the comparison group registered the same descending trend in VSH victimization. When further analyses that examined the program's effects while controlling for variables such as prior victimization, gender, race, grade (i.e., age), dating experience, and prior antiviolence program participation were conducted, for the most part, those exposed to treatment did not differ from the comparison group in terms of verbal sexual harassment victimization. This means that the program had no effect in reducing VSH victimization regardless of students receiving treatment or not. Moreover, treatment participants were significantly more likely to report cross-gender victimization when compared to the control group.

Taylor et al.'s (2012) experimental design randomly assigned schools and respondents to experimental and control groups to ensure the internal validity of the program evaluation. Yet, the current study had to exclude multiple cases because of missing information, which possibly led to selection bias as a potential threat to internal validity. In order to verify the stability of the findings obtained in multivariate analyses, a subsequent set of analyses was based on a selected sample that included two equivalent groups (experimental and control groups) created based on propensity score matching. By minimizing observable inter-group differences through the use of propensity score matching, the findings showed no significant difference in any type of VSH victimization 
between the experimental and control groups, in the direction anticipated by the Shifting Boundaries program. Furthermore, in one instance, as previously noted, a backfire effect (see Weisburd et al., 2003) could be noticed (i.e., treatment participants were significantly more likely to report cross-gender victimization than the comparison group). Although these findings were not anticipated, they are consistent with prior research, which concluded that, often, educational programs do not decrease adolescents' violence (Park-Higgerson, 2008) or produce mixed results, with short-term positive effects (Cornelius \& Resseguie, 2007; Meyer \& Stein, 2004). Nevertheless, some potential explanations for the unexpected results might exist. Even if PSM created equivalent groups, we do not know if contamination, a potential threat to the internal validity of the evaluation was not present. Contamination in social programs occurs when the "control group either actively or passively receives some or all of the intervention intended for the treatment group (Doyle \& Hickey, 2013, p. 183)," and if this was the case in the NYC study, the current findings might be partially explained. Additionally, it is possible that study participants did not differ from the comparison group or even expressed higher levels of victimization not necessarily because the program was ineffective. It is possible that students exposed to treatment had a higher capacity to recognize certain acts as examples of sexual harassment. In short, the program might have increased the students' level of awareness that made them more sensitive to verbal sexual harassment issues and influenced their self-reports. Nonetheless, although further research is needed to verify the program effectiveness, the relatively large proportion of students $(55 \%)$ who reported at least some type of VSH victimization after the program ended, is significant. 


\section{Limitations and Future Directions}

No study is without limitations; and so is the case for the current research. The results should be considered carefully in light of these limitations. First, generalizability from the current sample to the entire student body of middle schoolers across the United States is not possible. It is, however, possible that the results from this study are applicable to other large urban areas similar to New York City. What is also known is that very few studies have tackled sexual harassment among students in 6-12 grades (see Foshee et al., 2000; Taylor et al., 2010a, 2010b, 2012; Wolfe et al., 2009), and even fewer studies have addressed verbal sexual harassment, specifically (see Işik \& Kulakaç, 2015; Rolfe \& Schroeder 2017). Research should continue to examine sexual harassment among this population, especially verbal sexual harassment as it could be the gateway and training ground for students to establish a pattern of sexual harassment and violence into adulthood.

Second, the current study relied on self-reports obtained through pencil and paper surveys from students, which limited students from being able to provide the intensity and context of the verbal sexual harassment they either experienced or perpetrated toward their peers. Knowing the motivations or circumstances as well as distinguishing between offense and defense would shed more light on the incidences of verbal sexual harassment incidences. Students may have also had a difficult time remembering the details and timing of an event. They may have also underreported due to being embarrassed that they were a victim, a perpetrator, or both of verbal sexual harassment. Underreporting has been identified as an issue in sexual harassment research, especially with middle schoolaged children (AAUW, 2011; Taylor et al., 2013). For students of this age group to admit 
that verbal sexual harassment has occurred is contrary to their mechanisms to normalize and neutralize the victimization. To normalize and neutralize it as joking or playing around (Litchy \& Campbell, 2012) possibly means that students do not know how to identify it or its occurrences. Future sexual harassment programming and research should find a better way to instruct adolescents as to what constitutes as verbal sexual harassment from their peers and others, regardless of age.

And, there is also the possibility of students overreporting these behaviors. Despite these issues, confidential surveys have been used as the preferred and highly acceptable method for researchers to collect data on violence, including in randomized controlled experiments. The other issue with this self-report survey was its length. The survey was 12 pages long (256 questions), and students had only one class period (40 minutes) to complete the survey each time it was administered (pre-test, immediate posttest, and final post-test). The length of the survey and the placement of demographic questions being on the last page, resulted in a significant number of missing responses which led to a reduction in the sample size for the current study. Researchers in the future should consider surveys of a more reasonable length, placing questions related to respondent demographics in one of the first sections of the survey, use of electronic devices for students to complete and submit their responses, and to be more cognizant of the time needed for students of this age group to complete surveys.

Third, previous studies have documented that victims of sexual harassment can have long-term behavioral, emotional, and social consequences (Ackard \& NeumarkSztainer, 2002; Corbett et al., 1993; Exner-Cortens et al., 2013; Dahlqvist et al., 2016; Gruber \& Fineran, 2007; Parker \& Asher, 1987; Rhinehart et al., 2014) while in school, 
and for some, continue to follow them into adulthood (Espelage \& Holt, 2007; Halpern et al., 2009; McMaster et al., 2002). The present study was unable to document any potential detrimental effects of verbal sexual harassment because the data was absent from the survey. However, future examinations of the extent and nature of both verbal and physical sexual harassment should include analysis of the consequences of these two forms of sexual harassment and the similarities and differences of the consequences for each form of sexual harassment. This is important because it is quite possible that verbal sexual harassment is as significant to adolescent development as physical sexual harassment. Moreover, the ubiquity of verbal sexual harassment could be more damaging than physical sexual harassment for adolescents.

Fourth, the data for the current study only identified gender as binary (male and female), which means that when the author examined "prior dating experience," he could not distinguish between opposite-sex dating relationships and same-sex romantic relationships. Gender identity was not measured or included in the data. In the current research, one of the key predictors found to increase the odds of verbal sexual harassment victimization was for students who reported dating experience. However, it is possible that this effect is influenced by sexual and gender identity. We know that as adolescents age, they are more likely to explore their identity and sexuality, which consequently leads to an increase in sexual harassment incidences (McMaster et al., 2002; Peterson \& Hyde, 2009; Polce-Lynch et al., 2001). Therefore, future research should include more precise measures to examine adolescent sex scripts, gender identity, sexual orientation, and sexual activity. 
Fifth, the study was based on a secondary data analysis and potentially important explanatory variables (e.g., respondents' socioeconomic status; family background; nonpeer victimization) could not be included in the statistical models because they were not available. Having these explanatory variables would enrich research on verbal sexual harassment victimization and best practices to reduce or alleviate such behavior among this population.

The final limitation was the study did not differentiate between various educational programs, the timing, and the number of anti-violence programs students had attended prior to exposure to the current program. As previously mentioned, anti-violence programs are not universal in their design or application in our K-12 educational system. They can range from take-home pamphlets to a 1-day curriculum or longer and rarely include follow-up analysis to determine their effectiveness (Finkelhor et al., 2014). Moving forward, scholars need to use proper research designs that also include longitudinal data collection to determine the depth and breadth of the program's effectiveness to curtail sexual violence in our schools.

\section{Policy Implications}

Despite the limitations of this study, the findings provide several policy implications meant to reduce verbal sexual harassment victimization and promote overall safety within our K-12 educational system. We know that sexual harassment is an issue throughout our schools with 81 percent of students in grades 8-11 reporting they were victims of sexual harassment while at school, at least once in their lives (AAUW, 2011). Therefore, school-based programming should be implemented in every school across the 
country and implementation should start as early as late elementary school (i.e., $5^{\text {th }}$ grade). As studies have shown, the prevalence of sexual harassment starts at a much earlier age than high school (the focus of most programs) (Espelage et al., 2012; Wolitzky-Taylor et al., 2008). Additionally, programs should not be siloed into a specific type of violence (e.g., bullying, sexual harassment, sexual violence, dating violence, domestic violence, etc.) as the form often coincide with each other. A broader approach should be taken that reflects the stereotypes of our sex scripts and gender norms, including the complexities and overlap that is shared between victimizing and victimization.

Another policy strategy for school districts around the country would be to educate their administrators, teachers and staff on the differences between bullying and verbal sexual harassment. Far too often, staff and students minimize verbal sexual harassment as just joking around (Charmaraman et al., 2013), when in fact, the perpetrators are violating the rights of students because, unlike bullying, both verbal and physical sexual harassment violate federal law. Along with more education on the topic, Title IX policies should be enforced more rigorously by school administrators.

Students also need clear and concise programming that teaches them to define and recognize verbal sexual harassment. By doing so, they will be better equipped to protect themselves and others, as well as to report it to school officials.

Lastly, if students are to report incidents of sexual harassment, schools must develop and promulgate clear guidelines that promote safe outlets (i.e., liaison) for reporting such behaviors. 


\section{Conclusion}

Very few studies have been conducted on sexual harassment experienced by middle-school students, and even fewer have focused exclusively on verbal sexual harassment. The current study addressed both voids in the literature. Although more systematic research is needed, this study advanced our understanding of the cultural context and factors conducive to verbal sexual harassment victimization and highlighted the role of gender when examining differences between same- and cross-gender victimization.

Results suggest that societal gender norms (social scripts) in which the idea of masculinity drives cross-gender and/or same-gender victimization by adolescent males continue to be pervasive among youth in this large urban area. Moreover, while verbal sexual harassment victimization was found to affect more than half of the students in this study, students with dating experience had an increased risk of victimization. This suggests that one's pubertal development might have played an important role in differentiating victims of sexual harassment from non-victims, as prior research also found (McMaster et al., 2002; Petersen \& Hyde, 2009). The available data, however, did not offer information that could be used to determine if pubertal status influenced verbal sexual behavior or if other contextual factors linked to the dating culture increased one's vulnerability to victimization.

Surprisingly and different from what was hypothesized, neither pre-treatment exposure to an anti-violence educational program, nor participation in the Shifting Boundaries program predicted lower victimization levels in early adolescence. Nonetheless, these results should not be seen as indicative of the program's lack of 
effectiveness. In fact, these findings might only reflect the program's capacity to raise the students' awareness about sexual harassment, which in turn made them correctly interpret problematic behavior that otherwise would have passed unnoticed. However, as previously noted, it is imperative to implement anti-sexual harassment/anti-sexual violence programs using high methodological standards that would allow rigorous outcome evaluations. A review of the existing literature (Cornelius \& Resseguie, 2007; Meyer \& Stein, 2004) has shown the need for consistency in using rigorous experimental methodology in order to better predict overall program effectiveness and promote universal development of successful and effective programs.

Unlike bulling, sexual harassment is against the law. Educators should become more attuned to deciphering between the two, as well as using the tools provided to them through Title IX to address sexual harassment. If educators would show zero tolerance and stop labeling certain inappropriate acts as "innocent teasing" or "boys being boys", many more adolescents might be protected from verbal sexual harassment victimization. This is the ultimate goal, to reduce victimization through fostering gender equality among current and future generations of students and to expand our understanding of verbal sexual harassment by continued research that will inform sound intervention programs and policies aimed at harm reduction. After all, verbal sexual harassment is one of the primary avenues for early adolescents to test boundaries and consent, which, if left unchecked, could lead to future sexual violence. 


\section{REFERENCES}

Ackard, D. M., \& Neumark-Sztainer, D. (2002). Date violence and date rape among adolescents: Associations with disordered eating behaviors and psychological health. Child Abuse \& Neglect, 26, 455-473.

Alleyne-Green, B., Coleman-Cowger, V. H., \& Henry, D. B. (2012). Dating violence perpetration and/or victimization and associated sexual risk behaviors among a sample of inner-city African American and Hispanic adolescent females. Journal of Interpersonal Violence, 27, 1457-1473.

American Association of University Women. (1993). Hostile hallways: The AAUW survey on sexual harassment in America's schools. Washington, DC: American Association of University Women Educational Foundation.

American Association of University Women. (2001). Hostile hallways: Bullying, teasing, and sexual harassment in school. Washington, DC: American Association of University Women Educational Foundation.

American Association of University Women. (2011). Crossing the line: Sexual harassment at school. Washington, DC: American Association of University Women Educational Foundation.

Anderson, V. N., Simpson-Taylor, D., \& Herrmann, D. J. (2004). Gender, age, and rape-supportive rules. Sex Roles, 50, 77-90.

Anderson, L. A., \& Whiston, S. C. (2005). Sexual assault education programs: A meta analytic examination of their effectiveness. Psychology of Women Quarterly, 29(4), 374-388.

Archer, J. (2004). Sex differences in aggression in real-world settings: A meta-analytic review. Review of General Psychology, 8(4), 291.

Banyard, V. L., \& Cross, C. (2008). Consequences of teen dating violence: Understanding intervening variables in ecological context. Violence Against Women, 14(9), 998-1013.

Benson, D.J. \& Thomson, G.E. (1982). Sexual harassment on a university campus: the confluence of authority relations, sexual interest and gender stratification. Social Problems, 29 (3), 236-251. 
Berger, P. L. \& Luckman, T. (1966). Social Construction of Reality: A Treatise in the Sociology of Knowledge. Penguin Books: New York, New York.

Callahan, M. R., Tolman, R. M., \& Saunders, D. G. (2003). Adolescent dating violence victimization and psychological well-being. Journal of Adolescent Research, 18(6), 664-681.

Cantor, D., Fisher, B., Chibnall, S. H., Townsend, R., Lee, H., Thomas, G., \& Westat, Inc. (2015). Report on the AAU campus climate survey on sexual assault and sexual misconduct.

Charmaraman, L., Jones, A. E., Stein, N., \& Espelage, D. L. (2013). Is it bullying or sexual harassment? Knowledge, attitudes, and professional development experiences of middle school staff. Journal of School Health, 83, 438-444.

Chiodo, D., Wolfe, D. A., Crooks, C., Hughes, R., \& Jaffe, P. (2009). Impact of sexual harassment victimization by peers on subsequent adolescent victimization and adjustment: A longitudinal study. Journal of Adolescent Health, 45, 246-252.

Connell R. W. (1987). Gender and power: Society, the person and sexual politics. Cambridge: Polity Press.

Connell R. W. (2005). Masculinities. (2 ${ }^{\text {nd }}$ ed.). Cambridge: Polity Press.

Connell, R. W. (1996). Teaching the boys: New research on masculinity, and gender strategies for schools. Teachers College Record, 98(2), 206-235.

Connell, R. W., \& Messerschmidt, J. W. (2005). Hegemonic masculinity: Rethinking the concept. Gender \& Society, 19, 829-859.

Conte, A. (2010). Sexual Harassment in the Workplace: Sexuality, social relations, and the workplace (Vol. 1). Aspen Publishers Online.

Cooper, M. (2000). Being the 'go-to-guy': Fatherhood, masculinity, and the organization of work in Silicon Valley. Qualitative Sociology, 23(4), 379-404.

Corbett, K., Gentry, C. S., \& Pearson Jr, W. (1993). Sexual harassment in high school. Youth \& Society, 25(1), 93-103.

Cornelius, T. L., \& Resseguie, N. (2007). Primary and secondary prevention programs for dating violence: A review of the literature. Aggression and Violent Behavior, 12(3), 364-375. 
Crittenden, C.A., Gimlin, A.M., Bennett, A. \& Garland, T.S. (November 2, 2018). Exploring faculty and students' attitudes about consensual sexual relationships and sexual harassment on college campuses. Educational Policy, https://journals.sagepub.com/doi/10.1177/0895904818810522.

Dahlqvist, H. Z., Landstedt, E., Young, R., \& Gådin, K. G. (2016). Dimensions of peer sexual harassment victimization and depressive symptoms in adolescence: A longitudinal cross-lagged study in a Swedish sample. Journal of Youth and Adolescence, 45, 858-873.

DeGue, S., Valle, L. A., Holt, M. K., Massetti, G. M., Matjasko, J. L., \& Tharp, A. T. (2014). A systematic review of primary prevention strategies for sexual violence perpetration. Aggression and Violent Behavior, 19(4), 346-362.

De La Rue, L., Polanin, J. R., Espelage, D. L., \& Pigott, T. D. (2017). A meta-analysis of school-based interventions aimed to prevent or reduce violence in teen dating relationships. Review of Educational Research, 87(1), 7-34.

deLara, E. (2008). Developing a philosophy about bullying and sexual harassment: Cognitive coping strategies among high school students. Journal of School Violence, 7(4), 72-96.

Doyle, O. \& Hickey, C. (2013) The challenges of contamination in evaluations of childhood interventions. Evaluation, 19(2), 183-194.

Eaton, D. K., Kann, L., Kinchen, S., Shanklin, S., Flint, K. H., Hawkins, J., ... \& Whittle, L. (2012). Youth risk behavior surveillance-United States, 2011. Morbidity and Mortality Weekly Report: Surveillance Summaries, 61(4), 1-162.

Eaton, D. K., Kann, L., Kinchen, S., Shanklin, S., Ross, J., Hawkins, J., ... \& Lim, C. (2010). Youth risk behavior surveillance-United States, 2009. Morbidity and Mortality Weekly Report: Surveillance Summaries 59(5), 1-142.

Espelage, D. L., Basile, K. C., De La Rue, L., \& Hamburger, M. E. (2015). Longitudinal associations among bullying, homophobic teasing, and sexual violence perpetration among middle school students. Journal of Interpersonal Violence, $30,2541-2561$.

Espelage, D. L., Basile, K. C., \& Hamburger, M. E. (2012). Bullying perpetration and subsequent sexual violence perpetration among middle school students. Journal of Adolescent Health, 50, 60-65.

Espelage, D. L., \& Holt, M. K. (2007). Dating violence \& sexual harassment across the bully-victim continuum among middle and high school students. Journal of Youth and Adolescence, 36, 799-811. 
Espelage, D. L., Hong, J. S., Merrin, G. J., Davis, J. P., Rose, C. A., \& Little, T. D. (2018). A longitudinal examination of homophobic name-calling in middle school: Bullying, traditional masculinity, and sexual harassment as predictors. Psychology of Violence, 8(1), 57.

Espelage, D. L., Hong, J. S., Rinehart, S., \& Doshi, N. (2016). Understanding types, locations, \& perpetrators of peer-to-peer sexual harassment in US middle schools: A focus on sex, racial, and grade differences. Children and Youth Services Review, 71, 174-183.

Espelage, D., Low, S., Polanin, J., \& Brown, E. (2013). The impact of a middle school program to reduce aggression, victimization, and sexual violence. Journal of Adolescent Health, 53(2), 180-186.

Exner-Cortens D, Eckenrode J, Rothman E. (2013). Longitudinal Associations Between Teen Dating Violence Victimization and Adverse Health Outcomes. Pediatrics, 131(1), 71-78.

Fellmeth, G. L., Heffernan, C., Nurse, J., Habibula, S., \& Sethi, D. (2013). Educational and Skills-Based Interventions for Preventing Relationship and Dating Violence in Adolescents and Young Adults: A Systematic Review. Campbell Systematic Reviews, 9(1), i-124.

Ferguson, A. (2000). Bad boys: Public schools in the making of Black masculinity. Ann Arbor:University of Michigan Press.

Fineran, S., \& Bennett, L. (1999). Gender and power issues of peer sexual harassment among teenagers. Journal of Interpersonal Violence, 14, 626-641.

Fineran, S., McDonald, S., \& Constable, R. (2009). Bullying and peer sexual harassment in schools. Chicago, IL: Lyceum Books.

Finkelhor, D., Ormrod, R. K., \& Turner, H. A. (2007). Poly-victimization: A neglected component in child victimization. Child Abuse \& Neglect, 31(1), 7-26.

Finkelhor, D., Vanderminden, J., Turner, H., Shattuck, A., \& Hamby, S. (2014). Youth exposure to violence prevention programs in a national sample. Child Abuse \& Neglect, 38(4), 677-686.

Fitzgerald, L. F. (1993). Sexual harassment: Violence against women in the workplace. American Psychologist, 48(10), 1070.

Foshee, V. A., Bauman, K. E., Arriaga, X. B., Helms, R. W., Koch, G. G., \& Linder, G. F. (1998). An evaluation of Safe Dates, an adolescent dating violence prevention program. American Journal of Public Health, 88(1), 45-50. 
Foshee, V. A., Bauman, K. E., Greene, W. F., Koch, G. G., Linder, G. F., \& MacDougall, J. E. (2000). The Safe Dates program: 1-year follow-up results. American Journal of Public Health, 90(10), 1619.

Foshee, V. A., Bauman, K. E., Ennett, S. T., Linder, G. F., Benefield, T., \& Suchindran, C. (2004). Assessing the long-term effects of the Safe Dates program and a booster in preventing and reducing adolescent dating violence victimization and perpetration. American Journal of Public Health, 94(4), 619-624.

Foshee, V. A., \& Reyes, H. L. M. (2009). Primary prevention of adolescent dating abuse perpetration: When to begin, whom to target, and how to do it. In D. J. Whitaker \& J. R. Lutzker (Eds.), Preventing partner violence: Research and evidencebased intervention strategies (p. 141-168). American Psychological Association. https://doi.org/10.1037/11873-007

Gagnon, J. H., \& Simon, W. (1973). Sexual conduct: The social origins of human sexuality. Chicago, IL: Aldine.

Galesic, M., \& Tourangeau, R. (2007). What is sexual harassment? It depends on who asks! Framing effects on survey responses. Applied Cognitive Psychology: The Official Journal of the Society for Applied Research in Memory and Cognition, 21(2), 189-202.

Goffman, Irving (1959). Presentation of Self in Everyday Life. Doubleday: New York, New York.

Goffman, Irving (1967). Interaction Ritual: Essays in Face-To-Face Behavior. Pantheon Books: New York, New York.

Goffman, Irving (1974). Frame Analysis: An Essay on the Organization of Experience. Harvard University Press: Cambridge, Massachusetts.

Goldstein, S. E., Malanchuk, O., Davis-Kean, P. E., \& Eccles, J. S. (2007). Risk factors of sexual harassment by peers: A longitudinal investigation of African American and European American adolescents. Journal of Research on Adolescence, 17(2), 285-300.

Gramsci A. (1971. Selections from a Prison Notebook. London: Lawrence \& Wishart.

Green, E. L. (2019, September 12). Chicago public schools ordered to toughen sexual misconduct policies. New York Times.

Gruber, J. E., \& Fineran, S. (2007). The impact of bullying and sexual harassment on middle and high school girls. Violence Against Women, 13, 627-643. 
Gruber, J. E., \& Fineran, S. (2008). Comparing the impact of bullying and sexual harassment victimization on the mental and physical health of adolescents. Sex Roles, 59, 1-13.

Guo, S. \& Fraser, M. W. (2015). Propensity Score Analysis: Statistical Methods and Applications (2nd. Ed). Thousand Oaks, CA: Sage Publications

Gutek, B. A. (1985). Sex and the workplace (p. 46). San Francisco: Jossey-Bass.

Halpern, C. T., Spriggs, A. L., Martin, S. L., \& Kupper, L. L. (2009). Patterns of intimate partner violence victimization from adolescence to young adulthood in a nationally representative sample. Journal of Adolescent Health, 45, 508-516.

Hand, J. Z., \& Sanchez, L. (2000). Badgering or bantering? Gender differences in experience of, and reactions to, sexual harassment among U.S. high school students. Gender \& Society, 14, 718-746.

Hearn J., Nordberg M., Andersson K., Balkmar D., Pringle K., Forsberg L., Klinth R., Sandberg L. (2012). Hegemonic masculinity and beyond: 40 years of research in Sweden. Men and Masculinities, 15, 31-55.

Hickman LJ \& Jaycox LH, Aranoff J. (2004). Dating Violence Among Adolescents: Prevalence, Gender Distribution, and Prevention Program Effectiveness. Trauma, Violence, and Abuse, 5, 123-142.

Hill, C. \& Silva, E. (2005). Drawing the Line: Sexual Harassment on Campus. American Association of University of Women's Educational Foundation: Washington, D.C.

Holmes, W. M. (2014). Using propensity scores in quasi-experimental designs. Thousand Oaks, CA: Sage Publications.

Hlavka, H. R. (2014). Normalizing sexual violence: Young women account for harassment and abuse. Gender \& Society, 28, 337-358.

Hulin, C.L., L.F. Fitzgerald, F. Dragow (1996). Organizational influences on sexual harassment in Sexual Harassment in the Workplace: Perspectives, Frontiers \& Responses, Volume 5. M.S. Stockdale (Ed.). 127-150. Thousand Oaks, CA: Sage Publications.

Işik, I., \& Kulakaç, Ö. (2015). Verbal sexual harassment: A hidden problem for Turkish adolescent girls. Asian Journal of Women's Studies, 21, 431-449.

Jewks, R., Morrell, R., Hearn, J., Lundgvist, E., Blackbeard, D., Lindegger, G., Quayle, M., Sikweviya \& Gottzen, L. (2015). Hegemonic masculinity: combining theory and practice in gender interventions. Culture, Health \& Sexuality, 17 (2), 96-111. 
Jewkes R., Morrell R. (2012). Sexuality and the limits of agency among South African Teenage Women: Theorizing Femininities and Their Connections to HIV Risk Practices. Social Science \& Medicine, 74(11):1729-1737

Kadvany, E. (2017, March 13). OCR findings: A repeated failure to properly investigate. Palo Alto Online.

Kimmel, M. S. (1996). Manhood in America: A cultural history. New York, NY: Free Press.

Kimmel, M. S. (2007). The sexual self: The construction of sexual scripts. Nashville, TN: Vanderbilt University Press.

Klein, L.B. \& Martin, S.L. (October 21, 2019). Sexual harassment of college and university students: a systematic review. Trauma, Violence \& Abuse, https://doi.org/10.1177/1524838019881731.

Leff, S. S., Power, T. J., Manz, P. H., Costigan, T. E., \& Nabors, L.A. (2001). Schoolbased aggression prevention program for young children: Current status and implications for violence prevention. School Psychology Review, 30(3), 344.

Levine, E. (2017). Sexual violence among middle school students: The effects of gender and dating experience. Journal of Interpersonal Violence, 32(14), 2059-2082.

Lichty, L. F., \& Campbell, R. (2012). Targets and witnesses: Middle school students' sexual harassment experiences. Journal of Early Adolescence, 32, 414-430.

Lorber, J. (1994). Paradoxes of gender. New Haven: Yale University Press.

Lundgren, R., \& Amin, A. (2015). Addressing intimate partner violence and sexual violence among adolescents: Emerging evidence of effectiveness. Journal of Adolescent Health, 56(1), S42-S50. 18

McDonald, P. (2012). Workplace sexual harassment 30 years on: A review of the literature. International Journal of Management Reviews, 14(1), 1-17.

McMahon, J.J. (2019). Perceptions of sexual violence: an investigation of sexual harassment, sexual coercion, and sexting. Dissertation, Department of Clinical Psychology, The City University of New York.

McMaster, L. E., Connolly, J., Pepler, D., \& Craig, W. M. (2002). Peer to peer sexual harassment in early adolescence: A developmental perspective. Development and Psychopathology, 14, 91-105.

Meng, H. (2008). Social script theory and cross-cultural communication. Intercultural Communication Studies, 17(1), 132-138. 
Messerschmidt, J. W. (2000). Becoming "real men": Adolescent masculinity challenges and sexual violence. Men and Masculinities, 2, 286-307.

Messerschmidt, J. W. (2018). Hegemonic masculinity: Formulation, reformulation, and amplification. Rowman \& Littlefield.

Meyer, H., \& Stein, N. (2004). Relationship violence prevention education in schools: What's working, what's getting in the way, and what are some future directions. American Journal of Health Education, 35(4), 198-204.

Miller, J. (2008). Getting played: African American girls, urban inequality, and gendered violence. New York: New York University Press.

Morris, E. W. (2012). Learning the hard way: Masculinity, place, and the gender gap in education. New Brunswick, NY: Rutgers University Press.

Muehlenhard, C. L. (2011). Examining stereotypes about token resistance to sex. Psychology of Women Quarterly, 35, 676-683.

Ocampo, A. C. (2016). "Manning up to being gay”: Minority masculinities in the community and at the club. In C. J. Pascoe \& T. Bridges (Eds.), Exploring masculinities: Identity, inequality, continuity and change (pp. 301-310). New York: Oxford University Press.

Offenhauer, P., \& Buchalter, A. (2011). Teen dating violence: A literature review and annotated bibliography. The Library of Congress.

Oransky, M., \& Marecek, J. (2009). "I'm not going to be a girl": Masculinity and emotions in boys' friendships and peer groups. Journal of Adolescent Research, 24, 218-241.

Ormerod, A. J., Collinsworth, L. L., \& Perry, L. A. (2008). Critical climate: Relations Among sexual harassment, climate, and outcomes for high school boys and girls. Psychology of Women Quarterly, 32(2), 113-125.

Parker, J., \& Asher, S. R. (1987). Peer relations and later personal adjustment: Are low accepted children at risk? Psychological Bulletin, 102, 357-389.

Paechter, C. (2007). Being boys; being girls: Learning masculinities and femininities. London: McGraw-Hill Education.

Park-Higgerson, H. K., Perumean-Chaney, S. E., Bartolucci, A. A., Grimley, D. M., \& Singh, K. P. (2008). The evaluation of school-based violence prevention programs: A meta-analysis. Journal of School Health, 78(9), 465-479.

Pascoe, C. J. (2005). Dude you're a fag: Masculinity and sexuality in high school. Berkeley, CA: University of California Press. 
Pellegrini, A. D. (2001). A longitudinal study of heterosexual relationships, aggression, and sexual harassment during the transition from primary school through middle school. Applied Developmental Psychology, 22, 119-133.

Petersen, J. L., \& Hyde, J. S. (2009). A longitudinal investigation of peer sexual harassment victimization in adolescence. Journal of Adolescence, 32, 1173-1188.

Polce-Lynch, M., Myers, B. J., Kliewer, W., \& Kilmartin, C. (2001). Adolescent self esteem and gender: Exploring relations to sexual harassment, body image, media influence, and emotional expression. Journal of Youth and Adolescence, 30(2), 225-244.

Rhinehart, S., Doshi, N., \& Espelage, D. (2014). Sexual harassment and sexual violence experiences among middle school youth. Retrieved from http://www.ncdsv.org /images/AERA_Sexual-Harassment-and-SV-Experiences-Among-Middle-SchoolYouth_2014.pdfe

Reilly, M.E., Lott, B. \& Gallogly, S. M., (1986). Sexual harassment of university students. Sex Roles, 15, 33-358.

Reynolds, C. L. \& DesJardins, S. L. (2009). The use of matching methods in higher education research: Answering whether attendence at a 2-year institution results in differences in educational attainment. In J. C. Smart (ed.). Higher Education: Handbook of Theory and Research (pp. 47-97). New York: Springer.

Risman, B. J. (2004). Gender as a social structure: Theory wrestling with activism. Sociologists for Women in Society Feminist Literature, 18(4), 429-450.

Robinson, K. (2005). Reinforcing hegemonic masculinities through sexual harassment: Issues of identity, power and popularity in secondary schools. Gender and Education, 17, 19-37.

Rolfe, S. M., \& Schroeder, R. D. (2017). "Sticks and Stones May Break My Bones, but Words Will Never Hurt Me": Verbal Sexual Harassment Among Middle School Students. Journal of Interpersonal Violence, DOI: 0886260517709802.

Rosenbaum P.R. (2002) Observational studies. 2nd ed. New York, NY: Springer-Verlag

Rosenbaum, P. R., \& Rubin, D. B. (1983). The central role of the propensity score in observational studies for causal effects. Biometrika, 70, 41-55.

Rosenbaum, P. R., \& Rubin, D. B. (1985). Constructing a control group using multivariate matched sampling methods that incorporate the propensity score. The American Statistician, 39(1), 33-38. 
Rubin, D. B. (1974). Estimating causal effects of treatments in randomized and nonrandomized studies. Journal of Educational Psychology, 66, 688-701.

Schrock, D., \& Schwalbe, M. (2009). Men, masculinity, and manhood acts. Annual Review of Sociology, 35, 277-295.

Simon, W., \& Gagnon, J. H. (1986). Sexual scripts: Permanence and change. Archives of Sexual Behavior, 15(2), 97-120.

Sojo, V. E., Wood, R. E., \& Genat, A. E. (2016). Harmful workplace experiences and women's occupational well-being: A meta-analysis. Psychology of Women Quarterly, 40(1), 10-40.

St. Clair, R., Thome-Williams, A.C. \& Su, L. (2005). The role of social script theory in cognitive blending. Academia https://www.academia.edu/1601062/The role of social script theory in cogniti ve_blending

Stein, N. (1995). Sexual harassment in school: The public performance of gendered violence. Harvard Educational Review, 65, 145-162.

Stein, N. (2010). "Commentary: Sexual harassment left behind: What the 'bullying' framework is doing to civil rights laws and framework. Research and Action Report, Wellesley Centers for Women, 32: 6-7.

Stein, N. D., Marshall, N. L., \& Tropp, L. R. (1993). Secrets in public: Sexual harassment in our schools. Center for Research on Women, Wellesley College.

Stinson, R. D. (2010). Hooking up in young adulthood: A review of factors influencing the sexual behavior of college students. Journal of College Student Psychotherapy, 24, 98-115.

Taylor, B. G., Stein, N., \& Burden, F. F. (2010a). Exploring gender differences in dating violence/harassment prevention programming in middle schools: Results from a randomized experiment. Journal of Experimental Criminology, 6(4), 419-445.

Taylor, B., Stein, N., \& Burden, F. (2010b). The effects of gender violence/harassment prevention programming in middle schools: A randomized experimental evaluation. Violence and Victims, 25(2), 202-223.

Taylor, B., Stein, N., Mack, A. R., Horwood, T. J., \& Burden, F. (2008). Experimental Evaluation of Gender Violence/Harassment Prevention Programs in Middle Schools. Washington DC: National Institute of Justice.

Taylor, B. G., Stein, N. D., \& Mumford, E. A. (2013). Shifting boundaries: An experimental evaluation of a dating violence prevention program in middle schools. Prevention Science, 14, 64-76. 
Taylor, B. G., Stein, N. D., Woods, D., \& Mumford, E. (2012). Experimental evaluation of a youth dating violence prevention program in New York City middle schools, 2009-2010. Ann Arbor, MI: Inter-University Consortium for Political and Social Research [distributor], 05-18.

Thoemmes, F. (2012). Propensity score matching in SPSS. arXiv preprint arXiv:1201.6385.

Timmerman, G. (2003). Sexual harassment of adolescents perpetrated by teachers and by peers: An exploration of the dynamics of power, culture, and gender in secondary schools. Sex roles, 48(5-6), 231-244.

Ting, S. M. R. (2009). Meta-analysis on dating violence prevention among middle and high schools. Journal of School Violence, 8(4), 328-337.

Trigg, M., \& Wittenstrom, K. (1996). That's the way the world goes: Sexual harassment and New Jersey teenagers. Initiatives, 57, 55-65.

Tully, C. A. (2010). The influence of school climate on students' experiences of peer sexual harassment in high schools. Columbia University.

Uggen, C. \& Blackstone, A. (2004) Sexual harassment as a gendered expression. American Sociological Review, 69 (1), 64-92.

U.S. Department of Education, Office for Civil Rights. (1997). Sexual harassment guidance: Harassment of students by school employees, other students, or third parties. Federal Register, 62, 12034-12051.

U.S. Equal Opportunity Commission (March 24, 2020), Sexual Harassment. https://www.eeoc.gov/laws/types/sexual_harassment.cfm

Wedgwood, N. (2009). Connell's theory of masculinity - its origins and influences on the study of gender. Journal of Gender Studies 18(4), 329-339.

Wei, H.-S., \& Chen, J.-K. (2012). Factors associated with peer sexual harassment victimization among Taiwanese adolescents. Sex Roles, 66, 66-78.

Weisburd, D., Lum, C.M. \& Yang, S.M. (2003). When can we conclude that treatments or programs "Don't Work"? The Annals of the American Academy of Political and Social Science, 587: 31-48.

Wilkins, A. C. (2008). Wannabes, goths, and Christians: The boundaries of sex, style, and status. Chicago, IL: The University of Chicago Press.

Wise, S., \& Stanley, L. (1987). Georgie Porgie: Sexual harassment in everyday life. London, England: Pandora Press. 
Wolfe, D. A., Crooks, C., Jaffe, P., Chiodo, D., Hughes, R., Ellis, W., ... \& Donner, A. (2009). A school-based program to prevent adolescent dating violence: A cluster randomized trial. Archives of Pediatrics \& Adolescent Medicine, 163(8), 692-699.

Wolfe, D. A., Wekerle, C., Reitzel-Jaffe, D., \& Lefebvre, L. (1998). Factors associated with abusive relationships among maltreated and non-maltreated youth. Development and Psychopathology, 10, 61-85.

Wolff, J.M., Respenda, K.M. \& Colaneri, A.S. (2017). Sexual harassment, psychological distress, and problematic drinking behavior among college students: an examination of reciprocal causal relations. The Journal of Sex Research, 54(3), 362-373.

Wolitzky-Taylor, K. B., Ruggiero, K. J., Danielson, C. K., Resnick, H. S., Hanson, R. F., Smith, D. W., ... \& Kilpatrick, D. G. (2008). Prevalence and correlates of dating violence in a national sample of adolescents. Journal of the American Academy of Child \& Adolescent Psychiatry, 47(7), 755-762.

World Health Organization. (2010). Preventing intimate partner violence and sexual violence against women: Taking action and generating evidence. Retrieved from http://apps.who.int/iris/bitstream/10665/44350/1/9789241564007_eng.pdf 


\section{APPENDIX A}

\section{REPORTED VERBAL SEXUAL HARASSMENT VICTIMIZATION BY GENDER (Pre-test)}

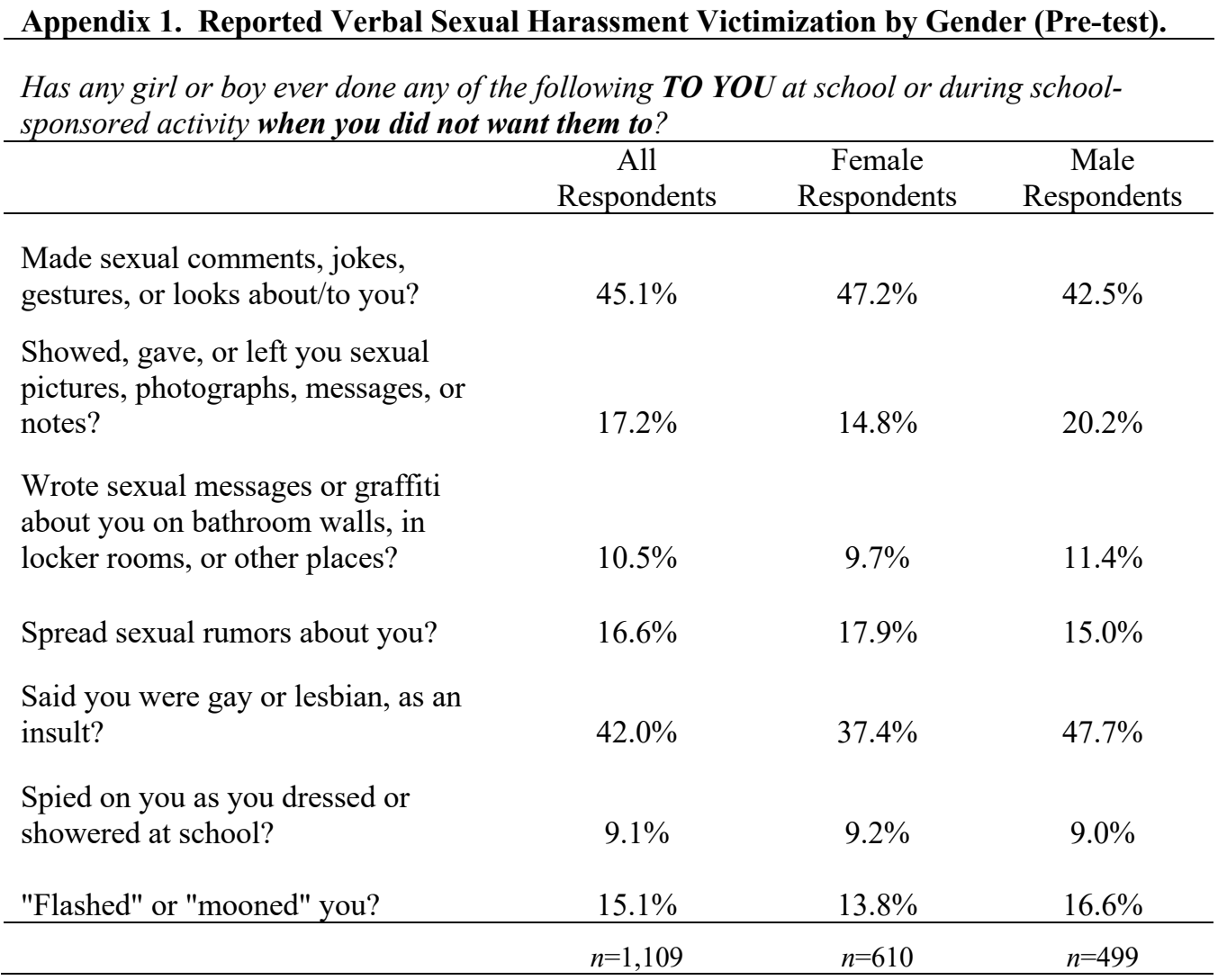




\section{APPENDIX B}

\section{REPORTED VERBAL SEXUAL HARASSMENT VICTIMIZATION BY GENDER (Post-test)}

\section{Appendix 2. Reported Verbal Sexual Harassment Victimization by Gender (Post-test).}

Has any girl or boy ever done any of the following TO YOU at school or during schoolsponsored activity when you did not want them to since the last survey?

All Female Male

Respondents Respondents Respondents

Made sexual comments, jokes, gestures, or looks about/to you?

$41.7 \%$

$45.1 \%$

$37.5 \%$

Showed, gave, or left you sexual pictures, photographs, messages, or notes?

$9.1 \%$

$10.7 \%$

$7.2 \%$

Wrote sexual messages or graffiti about you on bathroom walls, in locker rooms, or other places?

$5.6 \%$

$4.9 \%$

$6.4 \%$

Spread sexual rumors about you?

$13.5 \%$

$15.1 \%$

$11.6 \%$

Said you were gay or lesbian, as an insult?

$26.5 \%$

$22.1 \%$

$31.9 \%$

Spied on you as you dressed or showered at school?

$3.3 \%$

$3.0 \%$

$3.8 \%$

"Flashed" or "mooned" you?

$12.4 \%$

$12.8 \%$

$11.8 \%$

$n=1,109$

$n=610$

$n=499$ 


\section{APPENDIX C}

Dear Shawn Rolfe,

Thank you for your email. You may include the published version of your article (version 3 ) in your dissertation or thesis, which may be posted in an Institutional Repository or database as specified in our journal author reuse policy.

Please accept this email as permission for your request as you've detailed below. Permission is granted for the life of the edition on a non-exclusive basis, in the English language, throughout the world in all formats provided full citation is made to the original SAGE publication. Permission does not include any third-party material found within the work.

Please note that this permission does not cover any 3rd party material that may be found within the work. You must properly credit the original source, SAGE Publications, Inc., referencing the original publication and linking to the appropriate DOI where possible.

Please contact us for any further use of the material and good luck on your dissertation!

Kind regards,

Mary Ann Price

Rights Coordinator

SAGE Publishing

2600 Virginia Ave NW, Suite 600

Washington, DC 20037

USA

T: 202-729-1403

www.sagepublishing.com 


\title{
CURRICULUM VITAE
}

\author{
Shawn M. Rolfe \\ University of Louisville \\ Brigman Hall \\ Louisville, KY 40292 \\ 502-852-6567(office) \\ 650-709-3200 (cell) \\ shawn.rolfe@louisville.edu
}

\section{Education}

$2015-2020$

Ph.D. in Criminal Justice

University of Louisville, Louisville, Kentucky

Dissertation: Peer Verbal Sexual Harassment Victimization in Adolescents: A Feminist and Sexual Scripts Theoretical Approach.

Committee: Dr. Deborah Keeling, Ph.D. (Chair)

Dr. Viviana Andreescu, Ph.D. (Co-Chair)

Dr. Cherie Dawson-Edwards, Ph.D.

Dr. Ryan Schroeder, Ph.D.

$2013-2015$

\section{M.A. in Sociology}

University of Louisville, Louisville, Kentucky

Thesis: Another Collateral Consequence? Examining Homeless Shelters' Policies on Sex Offenders Across Four States.

Committee: Dr. Ryan Schroeder, Ph.D. (Chair)

Dr. David Roelfs, Ph.D. (Member)

Dr. Richard Tewksbury, Ph.D. (Member) 
B.A. in Sociology - cum laude

Wright State University, Dayton, Ohio

University and Sociology Department Honor Student

Minor: Crime and Justice Studies

Honor's Thesis: Sex Offenders and the Obstacles They Face

Reentering Society.

Committee: Dr. Karen Lahm, Ph.D. (Chair)

Dr. Michael Norris, Ph.D.

Dr. Jim Adamitis, Ph.D.

\section{Technical and Software Skills}

Quantitative and Qualitative Research Methodologies, Program Evaluation, Conceptualize and develop research proposals, IRB, grant writing, create surveys and interview questionnaires, recruit participants, conduct interviews, collect, clean, code and analyze data (including secondary datasets and Census Bureau data), write and present findings for all audiences.

Statistics: HLM, LISREL, STATA, SPSS w/syntax, ArcGIS

Publications

Peer-reviewed Journal Articles

Rolfe, Shawn M. (in-press). When a Sex Offender Comes to Visit: A National Assessment of Travel Restrictions. Criminal Justice Policy Review. DOI:10.1177/00887403417742948 (ResearchGate: over 18k reads; referenced by legislators, organizations, and the media)

Rolfe, Shawn M., and Ryan D. Schroeder. (in-press). "Sticks and Stones May Break My Bones, But Words Will Never Hurt Me": Verbal Sexual Harassment Among Middle School Students. Journal of Interpersonal Violence. DOI:10.1177/0886260517709802 (Media: The Age, Telegraph, Western Australia Today, and several others)

Baek, Hyunin, and Viviana Andreescu and Shawn M. Rolfe. (2019). Bullying and Fear of Victimization: Do Supportive Adults in School Make a Difference in Adolescents' Perceptions of Safety? Journal of School Violence 18(1), 92-106.

Rolfe, Shawn M., Richard Tewksbury, and Karen F. Lahm. (2018). Living Arrangements for Sex Offenders in Ohio: Effects of Economics, Laws, and Government Assistance Programs. The Prison Journal, 98(5), 544-559. 
Rolfe, Shawn M., and Richard Tewksbury and Ryan D. Schroeder. (2017). Homeless Shelters' Policies on Sex Offenders: Is This Another Collateral Consequence? International Journal of Offender Therapy and Comparative Criminology, 61(16), 1833-1849. (Highlighted and cited in several media outlets, and in an amicus brief filed with the U.S. Supreme Court, October 2018 - Bethea v. NC)

Higgins, Ethan M., and Shawn M. Rolfe. (2017). "The Sleeping Army": Necropolitics and the Collateral Consequences of Being a Sex Offender. Deviant Behavior, 38(9), 975-990.

Ross, Jeffrey I., and Richard Tewksbury and Shawn M. Rolfe. (2016). Inmate Response to CO Deviance and Misconduct: A Model of its Dynamic Nature. Corrections: Policy, Practice and Research, 1(2), 139-153.

Tewksbury, Richard., and Elizabeth E. Mustaine and Shawn M. Rolfe. (2016). Sex Offender Residential Mobility and Relegation: The Collateral Consequences Continue. American Journal of Criminal Justice, 41(4), 852-866.

(Media: Harvard Kennedy School's Journalist's Resource)

Book Chapter

Rolfe, Shawn M., and Richard Tewksbury (2018). Criminal Justice Policies: The Intended and Unintended Consequences of Monitoring Individuals Convicted of Sex Crimes. In Lussier, P. \& Beauregard, E. (Eds.). Sexual Offending: A Criminological Perspective. Abingdon, UK: Routledge/Taylor \& Francis.

Non-peer reviewed publications

Tewksbury, Richard and Shawn M. Rolfe. (2019). The Prison Rape Elimination Act. An Encyclopedia of Methods, Statistics, Criminology, and Criminal Justice.

Rolfe, Shawn M., and Richard Tewksbury. (2018). Violence in Prisons. American Prisons and Jails: An Encyclopedia of Controversies and Trends.

Rolfe, Shawn M. (February 2017). Aging Sex Offenders: Where do we put them? Spring Newsletter - Sexual Offense Policy Research.

Rolfe, Shawn M. (September 2016). Critical Review of Pervert Park. In ACJS Today.

Rolfe, Shawn M. (September 2016). Review of the Sixth Circuit U.S. Court Appeals Decision on Ex Post Facto on SORA Laws in Michigan. Fall Newsletter - Sexual Offense Policy Research. 
Rolfe, Shawn M. and Stephanie Jerstad. Does the Prison Time Fit the Sex Crime? Examining the Relationship Between Conviction Types and Incarceration Lengths for K-12 Educators Convicted of Sex Offenses.

Rolfe, Shawn M. Directors of Research Perceptions of Criminal Justice Graduate Programs.

Horowitz, Emily, and Shawn M. Rolfe. Military Veterans with Sex Offense Convictions: A Preliminary Investigation.

Works in Progress

Rolfe, Shawn M., and Emily Horowitz. Sexual Offending from Our Veterans: Is it A Military Culture Issue?

Rolfe, Shawn M. The Collateral Consequences of Sex Offender Registration and Notification Laws: Where We've Been, Are Now, and Future Directions.

Grant, Heath, and Shawn M. Rolfe. Does Social and Emotional Psychotherapy Work Behind Bars?

Rolfe, Shawn M. and Chris Dum. Why Do Emergency Homeless Shelters Prohibit Sex Offenders from Using Their Facilities? Interviews with the Directors from Ohio and Kentucky.

\section{Presentations}

Rolfe, Shawn M. What is Missing from Sex Offender Treatment Programming? Guest Speaker at the 2020 NYS ATSA and NYS Alliance for the Prevention of Sexual Abuse conference, Saratoga Springs, NY.

Rolfe, Shawn M., and Emily Horowitz. Sexual Offending from Our Veterans: Is it Due to Military Culture? Presented at the 2020 Academic Consortium on Criminal Justice Health conference, Raleigh, NC.

Horowitz, Emily, and Shawn M. Rolfe. Why Do Veterans Commit Sex Crimes? Presented at the 2020 Academy of Criminal Justice Sciences conference, San Antonio, TX.

Rolfe, Shawn M. National Travel Assessment of Travel Restrictions for Registered Sex Offenders. Presented at the 2019 Alliance for Constitutional Sex Offense Laws conference, LA, CA. 
Rolfe, Shawn M. What to Do or Not to Do When Traveling in the United States as a Registered Sex Offender. Presented at the 2019 National Association for Rational Sexual Offense Laws conference, Houston, TX.

Rolfe, Shawn M. An Ex-Con is Not Supposed to be Doing This: Obtaining a Doctorate Degree, Becoming a Scholar and Policy Advocate. Keynote Speaker for the 2019 Spring Lecture Series at St. Francis College, Brooklyn, NY

Rolfe, Shawn M. Does Sexual Harassment Programing Work? Examining the Effect of Sexual Harassment Programming Among Middle Schoolers. Presented at the 2018 American Society of Criminology conference, Atlanta, GA.

Rolfe, Shawn M. Reentry Issues for Justice-Involved People and Their Families. Presented at the 2018 H.E.A.L. Movement Gala, New York, NY.

Rolfe, Shawn M. Is Our Criminal Justice System Helping or Hurting Reentry Efforts for the Formerly Incarcerated? Keynote Speaker in 2018 for the Department of Sociology and Criminal Justice at St. Francis College, New York, NY.

Rolfe, Shawn M. How to Better Assist Those with a Criminal Background in North Carolina. Keynote Speaker for the 2018 Thrive GSO Annual Meeting, Greensboro, NC.

Rolfe, Shawn M. How Graduate School Does and Does Not Prepare Students to Work in Non-Academic Settings. Presented at the 2017 American Society of Criminology conference, Philadelphia, PA.

Rolfe, Shawn M., and Ryan D. Schroeder. "Sticks and Stones May Break My Bones, But Words Will Never Hurt Me": Verbal Sexual Harassment Among Middle School Students. Presented at the 2017 American Society of Criminology conference, Philadelphia, PA.

Sample, Lisa L., Tusty Ten Bensel, Shawn M. Rolfe, and Robert Lytle. Roundtable: Sexual Offense Policy Research. Presented at the 2017 Academy of Criminal Justice Sciences conferences, Kansas City, MO.

Rolfe, Shawn M., and Richard Tewksbury. Ivory Towers versus Boots on the Ground: An Examination of Non-Academic Researchers. Presented at the 2017 Western Society of Criminology conference, Las Vegas, NV.

Rolfe, Shawn M., and Richard Tewksbury. Travel Restrictions for Registered Sex Offenders Across the United States. Presented at the 2016 American Society of Criminology conference, New Orleans, LA. 
Rolfe, Shawn M., and David Patrick Connor. Does the Prison Time Fit the Teacher Sex Crime? Examining the Relationship between Incarceration Lengths and Conviction Types Among Educators Convicted of Sex Offenses. Presented at the 2016 Southern Criminal Justice Association conference, Savannah, GA.

Higgins, Ethan M., and Shawn M. Rolfe. "The Sleeping Army": Necropolotics and the Collateral Consequences of Being a Sex Offender. Presented at the 2016 Southern Criminal Justice Association conference, Savannah, GA.

Rolfe, Shawn M., Richard Tewksbury, and Elizabeth E. Mustaine. Downward Spiral of Housing Mobility for Registered Sex offenders. Presented at the 2016 Academy of Criminal Justice Sciences conference, Denver, CO.

Rolfe, Shawn M., Richard Tewksbury, and Ryan D. Schroeder. Homeless Shelters' Policies on Sex Offenders: Is this Another Collateral Consequence? Presented at the American Society of Criminology conference, Washington, D.C.

Rolfe, Shawn M., Richard Tewksbury, and Karen F. Lahm. Living Arrangements for Sex Offenders in Ohio: Effects in Living Arrangements, Economics and Government Assistance. Presented at the 2015 Southern Criminal Justice Association conference, Charleston, SC.

Rolfe, Shawn M., and Richard Tewksbury. Assessing the Collateral Consequences of SORN and Residency Restriction Laws on Employment for Registered Sex Offenders. Presented at the 2014 American Society of Criminal Justice conference, San Francisco, CA.

Rolfe, Shawn M. Another Collateral Consequence? Examining Homeless Shelters' Policies on Sex Offenders Across Four States. Presented at the 2014 Southern Criminal Justice Association conference, Clearwater Beach, FL.

Rolfe, Shawn M. Sex Offenders: Does Tier Designation Make a Difference Pertaining to Housing Availability? Presented at the 2013 American Society of Criminology conference, Atlanta, GA.

Rolfe, Shawn M. Sex Offenders and the Obstacles They Face Reentering Society. Presented at the 2013 Academy of Criminal Justice Sciences conference, Dallas, TX.

\section{Funding}

Awarded

2019 Recipient of the Richard Hamil Travel Award for ATSA New York

2017 University of Louisville, Graduate Student Council Research Grant: \$500.00 
2016 University of Louisville, Graduate Network in Arts and Sciences Grant: $\$ 500.00$

2016 University of Louisville, Graduate Network in Arts and Sciences Travel: $\$ 500.00$

2015 University of Louisville, Graduate Student Council Research Grant: \$300.00

2013 Wright State University, Sociology Research Grant: $\$ 750.00$

2012 Wright State University, Undergraduate Honors Research Grant: $\$ 400.00$

Unfunded

2015 National Science Foundation, Graduate Research Fellowship Program: \$150,000

Professional Experience

2018 - Present Independent Scholar

- Research literature on a variety of subject matters.

- Develop survey and interview questions, collect, manage, and analyze data.

- Present findings for a variety of outlets - peer-reviewed journals, symposiums, conferences, and to practitioners, stakeholders and policymakers.

- Develop relationships with practitioners, stakeholders, policymakers, and participants.

- Coordinate travel to meetings and conferences across the country.

$2017-2017$

Graduate Research Assistant to Dr. Deborah Keeling Department of Criminal Justice, University of Louisville

- Performed assigned tasks on research projects pertaining to public opinion of law enforcement, which includes but not limited to literature review searches, research questions, development of surveys, analysis of datasets, and writing of findings for various outlets.

2015 - 2017 Graduate Research Assistant to Dr. Richard Tewksbury Department of Criminal Justice, University of Louisville

- Conceptualized and wrote research proposals, IRB, grants and budgets.

- Collaborated with senior and junior researchers in the department and around the country.

- Nationally recruited participants, developed quantitative and qualitative instruments, collected, managed and analyzed 
$2013-2015$

$2012-2013$

$2011-2012$

$1999-2010$ datasets, as well cleaned, recoded, and analyzed secondary datasets - including Census Bureau data.

- Wrote for various medium outlets - including peer-reviewed journals.

- Presented the research in a number of forums (symposiums, conferences, practitioners, stakeholders, and policymakers).

- Coordinated travel for meetings and presentations across the country.

Graduate Assistant to Dr. Ryan D. Schroeder

Department of Sociology, University of Louisville

- Assisted and implemented the curriculum, syllabi, lectures, and grading.

- Conducted literature reviews and data analyses on secondary datasets.

- Wrote for various medium outlets - including peer-reviewed journals.

- Presented the research in a number of forums (symposiums, conferences, practitioners, stakeholders, and policymakers).

- Coordinated travel for meetings and presentations across the country.

Undergraduate Assistant Department of Sociology, Wright State University

- Assisted students with their departmental questions and needs.

- Guest lecturer and proctored exams.

Veterans Counseling Center, Veterans Administration Veterans Administration, Dayton, Ohio

- Set and manage appointments for veterans and counselors.

- Assisted veterans with their counseling needs and guided them to other VA services.

Employed in various business positions.

- Inside and outside salesman.

- Held middle and upper management positions.

- Met and exceeded sales goals both individually and as a manager.

- Managed and trained employees, oversaw operational budget, conducted training for new and current employees, gave presentations to management and other salesforce around the country. 
$1995-1999$

United States Marine Corps - Active Duty, Honorable Discharge

Camp LeJeune, North Carolina

- Trained and led junior marines to complete assigned missions.

\section{Teaching Experience}

$2013-2015 \quad$ Introduction to Sociology; Deviant Behavior; Juvenile Justice;

Volunteerism

Spring $2013 \quad$ Guest Lecture for graduate course ABS 7600

"Sex Offenders and the Laws"

Department of Sociology, Wright State University

Spring $2012 \quad$ Guest Lecture for SOC 200: Introduction to Sociology

Department of Sociology, Wright State University

Service

2019

New York's Sex Offender Policies and its Collateral

Consequences. WKRB 90.3 FM.

2018 - Present $\quad$ Researcher and Advocate - NC Second Chance Alliance

2018 - Present Researcher and Advocate - Convict Criminology

2017 - Present $\quad$ Committee Member - Formerly Incarcerated College Graduates Network

Media: Many names missing from the sex offender registry. (May 9, 2016). Dayton Daily News.

2015 - Present $\quad$ Founding Member and Board of Directors

Sexual Offense Policy Research

$2014-2015 \quad$ Treasurer

Sociology Graduate Student Association, University of Louisville

2014 - 2015 Department Representative

Graduate Student Council, University of Louisville 
Ad Hoc Reviewer

American Journal of Criminal Justice

Journal of Criminal Justice Policy Review

Journal of Criminal Justice Education

\section{Academic Honors and Awards}

2015 Outstanding Graduate Student

College of Arts and Sciences, University of Louisville

2015 Most Outstanding Graduate Researcher

Department of Sociology, University of Louisville

2014 Graduate Teaching Academy

University of Louisville

2013 Most Outstanding Senior

Department of Sociology, Wright State University

2013 Departmental Honors

Wright State University Honors

2012 Alpha Phi Sigma - Criminal Justice Honor Society

2012 Alpha Kappa Delta - International Honor Society of Sociology

2012 Phi Kappa Phi Honors Society

2011 Golden Key International Honor Society

Professional Memberships

2019 - Present $\quad$ Academic Consortium on Criminal Justice Health

2017 - Present $\quad$ Western Society of Criminology

2015 -Present $\quad$ Sex Offense Policy Research Working Group

2014 - Present $\quad$ Southern Criminal Justice Association

2012 - Present $\quad$ American Society of Criminology

2012 - Present Academy of Criminal Justice Sciences 


$\begin{array}{ll}2012 \text { - Present } & \text { American Sociological Association } \\ 2010 \text { - Present } & \text { American Veterans (AMVETS) } \\ 2002 \text { - Present } & \text { Disabled American Veterans } \\ 2000 \text { - Present } & \text { Veterans of Foreign Wars } \\ 2000 \text { - Present } & \text { American Legion }\end{array}$

